\title{
AHK5 mediates ETR1-initiated multistep phosphorelay in Arabidopsis
}

Agnieszka Szmitkowska ${ }^{1,2^{*}}$, Abigail Rubiato Cuyacot ${ }^{1,2^{*}}$, Blanka Pekárová1,2, Markéta Žd'árská ${ }^{1,2}$, Josef Houser $^{1,2}$, Jan Komárek ${ }^{1,2}$, Zuzana Jaseňáková ${ }^{1,2}$, Aswathy Jayasree ${ }^{1}$, Michael Heunemann ${ }^{5}$, Elena Ubogoeva ${ }^{3}$, loannis Spyroglou ${ }^{1}$, Martin Trtilek ${ }^{6}$, Victoria Mironova ${ }^{3,4,7}$, Klaus Harter ${ }^{5}$, Elena Zemlyanskaya $^{3,4}$, Lukáš Žídek ${ }^{1,2}$, Michaela Wimmerová ${ }^{1,2}$ and Jan Hejátko ${ }^{1,2}$

${ }^{1}$ CEITEC - Central European Institute of Technology, Masaryk University, Kamenice 753/5, CZ62500 Brno, Czech Republic, ${ }^{2}$ National Centre for Biomolecular Research, Faculty of Science, Masaryk University, Kamenice 753/5, CZ-62500 Brno, Czech Republic, ${ }^{3}$ Institute of Cytology and Genetics, Siberian Branch, Russian Academy of Sciences, Novosibirsk, 630090, Russia, ${ }^{4}$ Novosibirsk State University, Novosibirsk, 630090, Russia, ${ }^{5}$ Universität Tübingen, Center for Plant Molecular Biology (ZMBP), Auf der Morgenstelle 32 D-72076 Tübingen, Germany, ${ }^{6}$ Photon Systems Instruments, Drasov, Czech Republic, ${ }^{7}$ Department of Plant Systems Physiology, Institute for Water and Wetland Research, Radboud University, Heyendaalseweg 135, 6525, AJ Nijmegen, the Netherlands.

\section{*These authors contributed equally to this work.}

Correspondence and requests for materials should be addressed to J.H. (e-mail: jan.hejatko@ceitec.muni.cz)

\section{Summary}

Plants, like other sessile organisms, need to sense many different signals, and in response to them, modify their developmental programs to be able to survive in a highly changing environment. The multistep phosphorelay (MSP) in plants is a good candidate for a response mechanism that integrates multiple signal types both environmental and intrinsic in origin. Recently, ethylene was shown to control MSP activity via the histidine kinase (HK) activity of ETHYLENE RESPONSE 1 (ETR1) ${ }^{1,2}$, but the underlying molecular mechanism still remains unclear. 
Here we show that although ETR1 is an active $\mathrm{HK}$, its receiver domain $\left(E T R 1_{\text {RD }}\right)$ is structurally and functionally unable to accept the phosphate from the phosphorylated His in the ETR1 HK domain (ETR1 $1_{\text {HK }}$ ) to initiate the phosphorelay to ARABIDOPSIS HISTIDINE-CONTAINING PHOSPHOTRANSMITTERs (AHPS), the next link downstream members in MSP signaling. Instead, ETR1 interacts with another HK ARABIDOPSIS HISTIDINE KINASE 5 (AHK5) and transfers the phosphate from ETR1 $1_{H K}$ through the receiver domain of AHK5 (AHK5 $5_{R D}$ ), and subsequently to AHP1, AHP2 and AHP3, independently of the HK activity of AHK5. We show that AHK5 is necessary for ethylene-initiated, but not cytokinin-initiated, MSP signaling in planta and that it thus mediates hormonal control of root growth.

\section{Main}

In the MSP cascade, signal-driven autophosphorylation of the sensor HK on its conserved $\mathrm{His}$ triggers a downstream His-to-Asp-to-His-to-Asp phosphorelay, phosphorylating AHPs and type B response regulators (B-RRs) that consequently control signal-regulated transcription ${ }^{3}$. The first step in the MSP phosphorelay is an intramolecular transfer of a phosphate moiety from the phospho-His in the HK domain to the Asp of the RD within the sensor HK molecule. Previous studies have shown that ETR $1_{R D}$ is unlikely to be phosphorylated ${ }^{4}$, possibly being involved in phosphorylation-independent signalling ${ }^{5}$. In line with this, we did not detect any evidence of phosphate transfer (phosphorylation of ETR1 $1_{R D}$ or depletion of the radiolabeled phosphate from phosphorylated ETR1 $1_{\mathrm{HK}}$, see below) after two hours of incubation of autophosphorylated ETR1 $1_{\mathrm{HK}}$ in the presence of $E T R 1_{R D}$ (Supplementary Fig. 1A). Something similar, i.e. no detectable phosphotransfer, was observed when an ETR1 fragment comprising both HK and RD domain (ETR1 $1_{\text {HK-RD }}$ ) was autophosphorylated and used as a possible phosphate donor to AHP proteins (Supplementary Fig. 1B). To examine whether ETR1 $1_{\mathrm{RD}}$ is able to bind divalent cations that are essential for RD activation ${ }^{5,6}$, we conducted titration of ${ }^{15} \mathrm{~N}$-labeled ETR1 ${ }_{\mathrm{RD}}$ with $\mathrm{MgCl}_{2}$ or $\mathrm{MnCl}_{2}$ and monitored potential $\mathrm{Mg}^{2+} / \mathrm{Mn}^{2+}$ coordination by ETR $1_{\mathrm{RD}}$ residues by measuring ${ }^{1} \mathrm{H}_{-}{ }^{15} \mathrm{~N}$ heteronuclear single quantum coherence (HSQC) NMR spectra. Comparison of the HSQC spectra of ETR1 $1_{\mathrm{RD}}$ in its free form and in the presence of $\mathrm{Mg}^{2+}$ and $\mathrm{Mn}^{2+}$ ions (Supplementary Fig. $1 \mathrm{C}, \mathrm{D}$ ) revealed only negligible changes in peak positions $\left(\mathrm{MgCl}_{2}\right)$ and peak intensities $\left(\mathrm{MnCl}_{2}\right)$, indicating 
that $\mathrm{ETR} 1_{\mathrm{RD}}$ binds neither $\mathrm{Mg}^{2+}$ nor $\mathrm{Mn}^{2+}$. This was further supported by microscale thermophoresis (MST), where no sign was observed of $\mathrm{Mg}^{2+}$ or $\mathrm{Mn}^{2+}$ binding to the fluorescently labelled ETR1 $1_{\mathrm{RD}}$ over the range of concentrations tested (up to $50 \mathrm{mM} \mathrm{Mg} \mathrm{Mg}^{2+} / \mathrm{Mn}^{2+}$, data not shown). Altogether, these results suggest that $\mathrm{ETR} 1_{\mathrm{RD}}$ is unable to mediate phosphotransfer in ETR1-mediated MSP signaling.

The recently demonstrated ability of ETR1 to control MSP via its HK activity ${ }^{1,2}$ implies that ETR1 $1_{\mathrm{HK}}$ may phosphorylate RD of other receptors active in MSP. To test this possibility, we performed a series of phosphotransfer assays with various RDs from Arabidopsis sensor HKs. We selected RD of the well-studied cytokinin receptor AHK4 (AHK4 $\left.4_{R D}\right)$ and RDs from the two subclades of noncytokinin HK sensors CKI1 and AHK5 ( $C K I 1_{R D}$ and $A H K 5_{R D}$, respectively), as $A H K 5_{R D}$ is the closest paralogue of ETR1 $1_{\mathrm{RD}}$ (Supplemental Fig. 2 and 3). After 30 minutes of incubation, we observed phosphotransfer from ETR1 $1_{\mathrm{HK}}$ (manifested as loss of ETR1 $1_{\mathrm{HK}}$ phosphorylation, see Supplemental Fig. 4A) to all three RDs at all molar ratios tested. As anticipated, presence of higher RD concentrations led to more apparent loss of ETR1 $1_{\mathrm{HK}}$ phosphorylation, suggesting faster phosphotransfer. The most efficient phosphotransfer by far was observed for AHK5 $5_{\text {RD }}$, followed by $C K I 1_{R D}$ and $A H K 4_{R D}$ (Supplemental Fig. $4 A$ ). The phosphorylated $A H K 5_{R D}$ signal was not detectable after 30 min of incubation, possibly due to fast RD autodephosphorylation activity driving rapid phosphoaspartate hydrolysis ${ }^{7}$. However, phosphorylated $\mathrm{CKI} 1_{\mathrm{RD}}$ and AHK $4_{\mathrm{RD}}$ seem to be more stable as the bands corresponding to the phosphorylated forms of both RDs were visible at all ratios tested. Compared to long (30 min) incubation, phosphorylated $A H K 5_{R D}$ was clearly detectable as early as $30 \mathrm{~s}$ after addition of $A H K 5_{R D}$, as also the decrease in intensity of radiolabeled $\mathrm{ETR} 1_{\mathrm{HK}}$ at the shorter intervals (Fig. $1 \mathrm{~A}$ ). In contrast, $\mathrm{CKI} 1_{\mathrm{RD}}$ and $A H K 4_{\mathrm{RD}}$ were both phosphorylated only very weakly even after $40 \mathrm{~min}$ of incubation at a molar ratio of 1:2 (Fig. 1B, Supplemental Fig. 4B). Quantification of phosphotransfer kinetics from phosphorylated ETR1 $1_{\mathrm{HK}}$ to $\mathrm{AHK}_{\mathrm{RD}}$ and $\mathrm{CKI} 1_{\mathrm{RD}}$ (Figs. 1C, D, Supplemental Fig. 5; see also Methods) confirmed that ETR1 exhibits strong kinetic preference for $\mathrm{AHK}_{\mathrm{RD}}$ in vitro. Additional experiments with $\mathrm{ETR} 1_{\mathrm{HK}-\mathrm{RD}}$ as a phosphate donor (Supplemental Figs. 4C, D) demonstrated that the presence of ETR $1_{R D}$ does not prevent the ability of ETR $1_{H K}$ to phosphorylate any of the RDs tested. However, AHK $5_{R D}$ was able to accept the phosphate faster from ETR1 $1_{\mathrm{HK}}$ than from ETR1 $1_{\mathrm{HK}-\mathrm{RD}}$ (Fig. 1D). Hence, a possible 
regulatory role for $E T R 1_{R D}$ in $E T R 1_{H K}-$ mediated phosphorylation cannot be excluded. We can thus conclude that $A H K 5_{R D}$ is likely the canonical substrate for the histidine kinase-dependent signaling activity of ETR1.

To test for possible ETR $1_{H K} / A H K 5_{R D} / A H P s$ phosphorelay, equimolar amounts of $A H P s$ and $A H K 5_{R D}$

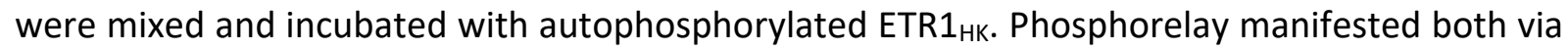
(i) disappearance of phosphorylated $\mathrm{ETR} 1_{\mathrm{HK}}$ and (ii) emergence of signal corresponding to phosphorylated AHK5 $5_{\mathrm{RD}}$ and the AHPs (Fig. 1E). Phosphotransfer from ETR $1_{\mathrm{HK}}$ to AHK5 $5_{\mathrm{RD}}$ and all AHPs was almost immediate (just after mixing together the individual reaction components, time " 0 " in Fig. 1E), confirming in vitro functionality and high efficiency of ETR1 $1_{\mathrm{HK}} / \mathrm{AHK}_{\mathrm{RD}} / \mathrm{AHPs}$ phosphorelay. Replacing the phosphoaccepting Asp 828 of $A H K 5_{R D}$ to the non phosphorylatable Ala (in the D828A mutant of $A H K 5_{\mathrm{RD}}$ ) abolished phosphotransfer from ETR1 $1_{\mathrm{HK}}$ to both $\mathrm{AHK} 5_{\mathrm{RD}}$ and AHPs (Fig. 1F), thus confirming the His-to-Asp mechanism of the first transphosphorylation within the ETR1 $1_{\mathrm{HK}}$-induced phosphorelay. Importantly, the native AHK5 HK domain in the AHK5 $5_{\mathrm{HK}-\mathrm{RD}}$ protein does not prevent the ability of $\mathrm{ETR} 1_{\mathrm{HK}}$ to phosphorylate $A H K 5_{\mathrm{RD}}$ (Fig. 1G). AHK5 $5_{\mathrm{HK}-\mathrm{RD}}$ is able to autophosphorylate and transfer the phosphate (via its own RD) to AHP2 (Supplemental Fig. 6). However, while the conserved $\mathrm{His} 382$ of $\mathrm{AHK} 5_{\mathrm{HK}}$ is necessary for the autokinase activity of AHK5 HK-RD and AHK5-mediated phosphorylation of AHP2 (Supplemental Fig. 6), it is not

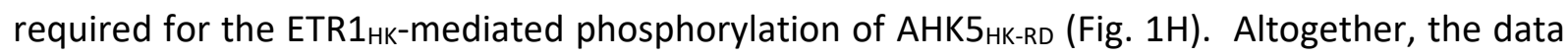
convincingly demonstrate that ETR1 $1_{\mathrm{HK}}$ is able to initiate the His-to-Asp-to-His phosphorelay, allowing the phosphorylation of AHPs via AHK5 ${ }_{R D}$ independently of the HK activity of AHK5.

Despite the similarities in the overall structures, the ETR $1_{R D}$ protein differs from other known bacterial, yeast and plant RDs in the orientation of its $\beta 3-\alpha 3$ loop (also called $\gamma$-loop). Compared to all other (including bacterial and yeast) RDs of known structure, the $\gamma$-loop of ETR $1_{R D}$ is flipped over to face the opposite side ${ }^{8,9}$ (Fig. 2A). Sequence analysis showed that the $\gamma$-loop of ETR $1_{\text {RD }}$ differs from the $\gamma$-loop of AHK5 RD $_{\text {and }}$ other Arabidopsis RDs (Supplemental Fig. 3). To unravel the possible functional importance of this sequence variation, we introduced several mutations (namely G664V, V665L, E666D, and N667G) to rewire the sequence of the ETR1 $1_{R D} \gamma$-loop to resemble that of $A H K 5_{R D}$. Further, we mutated Val 711 of ETR1 $1_{R D}$ to Phe, found in the 
corresponding position (903) of $A H K 5_{R D}$. F903 stabilizes the orientation of T884 during phosphorylation of $A H K 5_{R D}$ through F-T-coupling ${ }^{10}$. However, even the quintuple mutant ETR $1_{R D}$ G664V V665L E666D N667G V711F was not able to accept phosphate from autophosphorylated ETR1 $1_{\mathrm{HK}}$ (Supplemental Fig. 7). To investigate the effect of introduced mutations on the structure of ETR1 $1_{R D}$, we crystalized both wild type $(W T)$ and mutant ETR $1_{R D}$. The structure of WT ETR $1_{R D}$ was determined at $1.5 \AA$ resolution (PDB 7PN2). With the exception of the C-terminus position, only minor changes in the orientation of flexible $\beta 3-\alpha 4$ loop were observed when compared to the previously published structure of ETR $1_{\text {RD }}$ [solved at lower $\left(2.5 \AA\right.$ ) resolution, PDB 1 DCF ${ }^{9}$ (Fig. 2A)]. In the quintuple mutant ETR1 $1_{\text {RD }}$ G664V V665L E666D N667G V711F, the structure refined at $1.9 \AA$ (PDB 7PN3) showed increased flexibility of the $\gamma$-loop when compared to the WT while retaining a similar orientation (Fig. 2B, Supplemental Table 1). To sum up, our structural data are in line with the functional assay, confirming the inability of ETR1 $1_{R D}$ to accept phosphate from its native HK domain and suggest that molecular determinants of the observed structural and functional diversity are to be found outside the $\gamma$-loop of ETR1 $1_{\mathrm{RD}}$.

Since ETR1 $1_{\mathrm{HK}}$ phosphorylates $A H K 5_{\mathrm{RD}}$, we investigated the interaction between these proteins in vitro by MST and fluorescent anisotropy (FA) assays. Binding curves were measured by titration experiments where ETR1 $1_{H K}$ or ETR $1_{H K-R D}$ was added to fluorescently labelled $A H K 5_{R D}$. Results of both assays (Fig. $3 \mathrm{~A}$ and Supplemental Fig. 8) show that ETR1 $1_{\mathrm{HK}}$ interacts with AHK5 $5_{\mathrm{RD}}$ albeit with low affinity. Interaction between the cytoplasmic part of ETR1 (ETR1 without transmembrane domain, $\triangle$ TM-ETR1) and full length AHK5 in planta has been assayed using FLIM-FRET. Statistically highly significant shortening ( $\alpha=9.05 \times 10^{-9}$ and $5.5 \times 10^{-10}$, respectively) of $\Delta \mathrm{TM}$ ETR1-GFP fluorescence lifetimes was detected in the presence of AHK5, tagged either N- or Cterminally with mRFP1 (Figs. 3B, C). Similar results were obtained in the FLIM-FRET assay using full length AHK5-GFP and ETR1-mCherry (Supplemental Fig. 9). These results prove that ETR1 associates with AHK5 in planta, allowing ETR1/AHK5/AHPs phosphorelay.

In order to assess the possible role of AHK5 in ethylene-regulated MSP signaling in Arabidopsis, we assayed the expression pattern of MSP reporter TCSn:GFP'11 and its responsiveness to both cytokinins and ethylene in both WT and ahk5-1 mutant backgrounds. As demonstrated 
previously ${ }^{2,11}$, the TCS signal locates mostly to the columella/lateral root cap (LRC) in mocktreated WT roots, while a weak signal is seen in the stele cells located proximally to the quiescent center (QC; Fig. 4A). Treatment with cytokinin ([5 $\mu \mathrm{M}$ 6-benzylaminopurine (BAP) for $24 \mathrm{~h}]$ upregulated the TCS signal throughout the root tip, i.e. in the stele, columella/LRC and epidermis/cortex of the root transition zone (TZ; Fig. 4A, Supplemental Figs. 10B-D). In line with a recent report ${ }^{2}$, 1-aminocyclopropane-1-carboxylic acid (ACC) - the rate-limiting precursor of ethylene biosynthesis - upregulated TCS preferentially in the root TZ. A relatively weaker activation (compared to mock-treated control) of MSP signaling was detected in the columella/LRC. In cases of combined treatment with cytokinin and ACC, most of the observed effects were cytokinin-like (Fig. 4A, Supplemental Fig. 10D). Strikingly, the absence of AHK5 almost completely abolished TCSn:GFP activity in the root, and only a weak signal was still apparent in the stele in mock-treated ahk5-1 (Fig. 4B, Supplemental Fig. 10E). Further, the TCSn:GFP response of ahk5-1 to cytokinin was comparable to WT, with an even slightly higher level of activation in the stele and root TZ. In contrast to this, ACC was able to induce TCS only in the root TZ and only weakly in the stele, but the signal was either weak or undetectable in the columella/LRC of ahk5-1, irrespective of whether ACC was present or not. This suggests that functional AHK5 is necessary for ethylene-induced MSP activity in the columella/LRC, but not for MSP induced by cytokinin in the same tissue. The role of ethylene in MSP signaling in the columella/LRC was further substantiated by downregulation of the TCSn:GFP signal in WT following treatment with either 2-aminoethoxyvinyl glycine (AVG), an inhibitor of ethylene biosynthesis or 1-methylcyclopropene (1-MCP), an ethylene antagonist that prevents ethylene binding to its receptors ETR1 and ERS1 ${ }^{12}$ (Fig. 4C, Supplemental Figs. 10A, F).

Ethylene was shown to control cell divisions in the quiescent center (QC) resulting in changes in the number of columella layers ${ }^{13}$. Accordingly, we found an additional columella cell layer in ACCtreated ahk5-1 when compared to Col-0 (Supplemental Fig. 10G). Interaction between the activity of QC/columella initials, the number of root cap cells and their release as border cells in pea and border-like cells in Arabidopsis ${ }^{14}$ was shown to be under auxin and ethylene control ${ }^{15,16}$. We observed that while ACC slightly upregulated the number of border-like cells in WT, the opposite response, i.e. strong downregulation, was observed in ACC-treated ahk5-1 (Fig. 4D). 
Recently, ETR1-mediated MSP was shown to control root apical meristem (RAM) size by controlling cell differentiation in the root $\mathrm{TZ}^{1,2}$. Higher TCS induction by both cytokinin and ethylene observed particularly in the root TZ but also in the stele of ahk5-1 (Supplemental Figs. 10D, E), implies a possible role for AHK5 also outside the columella/LRC. Accordingly, we found longitudinal expansion of the RAM proliferative region [also called proximal meristem $(\mathrm{PM})^{17}$ ] in ahk5-1 under control conditions. ahk5-1 seedlings grown in the presence of ACC showed shortening of both RAM and TZ, which is in contrast to WT that was ACC-insensitive under these conditions (Figs. 4E, F). In agreement with these results, ahk5-1 was more sensitive to ACC than WT also at the level of the root elongation (Supplemental Fig. 10H). Taken together, our data show that AHK5 is necessary for ethylene-mediated control of MSP signaling in the columella/LRC. Further our data underline that AHK5 is a negative regulator of cell number in the proliferative region of the RAM and attenuates both ethylene-regulated responses in columella/LRC as well as the ethylene-controlled RAM/TZ size.

\section{Discussion}

Here we provide direct functional and structural evidence that although ETR1 is an active HK, ETR1 $1_{\mathrm{RD}}$ is unable to accept a phosphate moiety from phosphorylated ETR1 $1_{\mathrm{HK}}$. This could possibly be due to the high conformational rigidity and the different orientation of the ETR $1_{\text {RD }} \gamma$-loop ${ }^{4,5}$. Instead, ETR1 forms a complex with AHK5, another HK, and ETR1 $1_{\mathrm{HK}}$ phosphorylates $A H K 5_{\mathrm{RD}}$ to initiate an ETR1/AHK5/AHPs phosphorelay. To our knowledge, this is the first example of signaling crosstalk mediated by transphosphorylation activity between two different sensor HKs (Fig. 4G) anywhere in the kingdoms employing MSP or related two-component signaling (bacteria, fungi and plants). A partially similar mechanism was described in Pseudomonas aeruginosa, where the RetS HK inhibits the activity of another HK GacS by three different mechanisms, each of which requires direct protein-protein interaction ${ }^{18,19}$. In contrast to the originally proposed model, the formation of a non-productive heterodimer between RetS and GacS has been recently excluded ${ }^{20}$. This type of interaction was recently described also in rice, where the ethylene sensor OsERS2 was shown to interact with the rice AHK5 orthologue 
MHZ1/OsHK1 and control its HK activity ${ }^{21}$. Nevertheless, transphosphorylation was not reported as a mechanism of the interaction either in the Pseudomonas or in the rice signaling systems, i. e., between RetS or OsERS2 and their downstream regulatory targets. Our data show direct interaction between ETR1 and AHK5, both in vitro and in vivo. Based on the known structural model of ETR1 and the complex between HK853 and its cognate RR RR468 22 , formation of a heterodimer between ETR1 and AHK5 seems to be the most plausible mechanistic model for explaining the observed phosphorelay from ETR $1_{H K}$ to $A H K 5_{R D}$. While covalently-linked ETR1 homodimer formation is not necessary for ethylene binding ${ }^{23}$, further corroborating the possibility of functional heterodimer formation, the existence of higher order complexes (e.g. the dimer/dimer) cannot be excluded by our data (Fig. 4G).

ARR2, the type-B RR, was found to be phosphorylated in an ETR1-dependent manner ${ }^{24}$. Interestingly, AHK5 seems to act together with ETR1 in the $\mathrm{H}_{2} \mathrm{O}_{2}$-dependent control of stomata closure $^{25,26}$ and ARR2 or AHP1, AHP2 and AHP3 were proposed to mediate the response downstream of ETR1 and AHK5, respectively ${ }^{26,27}$. AHP1-3 have been shown to physically interact with $A H K 5_{\mathrm{RD}}$ in planta ${ }^{10}$ and with ARR2 in yeast ${ }^{28,29}$. Thus, our data showing the ability of ETR $1_{\mathrm{HK}}$ to phosphorylate AHP1, AHP2 and AHP3 through AHK5 RD are well in line with these observations, providing a mechanical window into the ETR1/AHK5/AHPs phosphorelay. Our results imply that AHK5 is a negative regulator of RAM size and a number of other ethylene-mediated responses including cell number regulation of columella/border-like cells and RAM and TZ shortening (Fig. $4 \mathrm{H})$. This is also in agreement with the previously proposed negative role for AHK5 in ETR1dependent ABA- and ethylene-mediated inhibition of root growth ${ }^{30}$. Apart from these, AHK5 has been shown to be a positive regulator of ethylene-induced stomata closure ${ }^{25}$. This implies that ETR1/AHK5 phosphorelay may act in a tissue-specific fashion, but the molecular mechanism behind this remains to be elucidated.

We demonstrate that AHK5 activity is critical for basal MSP signaling in the LRC/columella, representing most of the MSP signaling observed in the non-treated Arabidopsis roots. In LRC/columella cells, AHK5 mediates ethylene-induced, but not cytokinin-induced, MSP activation, and interferes with the ethylene-driven regulation of the number of columella cells 
and border-like cells detachment. Border and border-like cells are of paramount importance for root interaction with the soil microbiome and for protecting the root against biotic and abiotic stresses $^{31,32}$. The release of border cells also facilitates root penetration through the soil by decreasing frictional resistance ${ }^{33}$. Recently, a role was proposed for ethylene in the inhibition of root growth through compacted soil ${ }^{34}$. The ethylene-inhibited release of border-like cells seems to represent another mechanism of ethylene-controlled root growth navigation in mechanically heterogeneous soil conditions, and as such, a potentially highly valuable crop breeding trait. However, our data show that AHK5 also acts outside the LRC/columella. Ethylene was shown to control root growth predominantly via the regulation of auxin biosynthesis and intercellular auxin distribution ${ }^{35-38}$. Importantly, MSP-regulated auxin accumulation specifically in the LRC was shown to be involved in the control of RAM size ${ }^{39}$. Thus, the AHK5-mediated regulation of auxin homeostasis in the LRC might be the mechanism through which AHK5 controls the RAM proliferation zone, and this could be partially ethylene-independent (Fig. 4G, H).

The absence of transmembrane and extracellular domains makes AHK5 an ideal partner for ETR1, which lacks a functional RD. This type of direct crosstalk between two sensor HKs seems to add a combinatorial aspect to the highly modular MSP signaling, thus widening the spectrum of signals that can potentially be integrated employing a single signaling mechanism. This type of signal integration seems to be important mainly for organisms living in highly variable conditions, including pathogenic bacteria as for instance the aforementioned RetS/GatS example, or typically for sessile organisms like plants. It still remains an open question as to whether AHK5 is able to integrate signal(s) from other HKs.

\section{Methods}

\section{Phylogenetic analysis}

Protein sequences of seven Arabidopsis histidine kinases (ETR1 [UniProtKB ID: P49333], AHK1 [Q9SXL4], AHK2 [Q9C5U2], AHK3 [Q9C5U1], AHK4 [Q9C5U0], AHK5 [Q3S4A7], and CKI1 [022267]) were retrieved from the TAIR database (https://www.arabidopsis.org). C-terminal receiver 
constructed using the Clustal Omega algorithm without additional constraints ${ }^{41}$. The phylogenetic tree was constructed using the Maximum Likelihood method based on the JTT matrix-based model in Mega 7 software ${ }^{42}$. Bootstrap values from 1,000 trials were used. The tree is drawn to scale, with branch lengths measured in the number of substitutions per site. All positions containing gaps and missing data were eliminated. There were a total of 115 positions in the final dataset.

\section{Cloning and mutagenesis}

DNA constructs for protein expression of AHPs, $A H K 5_{R D}, C K I 1_{R D}, A H K 4_{R D}$, and ETR1 $1_{H K}$ were prepared as reported earlier $8,43,44$. Two constructs were prepared for the production of ETR $1_{\mathrm{RD}}$ protein: (i) ETR1 $1_{\mathrm{RD}}$ in the expression vector pETm60-Ub2 (amino acid residues 609-738); the product was used in kinase assays and (ii) ETR1 $1_{R D}$ in the pHYRSF53(Sumo)LA vector (amino acid residues 605-738); the product was used in kinase assays, for crystallization and in NMR experiments. The DNA construct in pETM60-Ub2 was prepared as reported ${ }^{44}$. The DNA fragments encoding ETR1 $1_{\mathrm{RD}}$ (605-738), ETR1 $1_{\text {HK-RD }}$ (324-738), and AHK5 ${ }_{\text {HK-RD }}$ (300-922) were amplified from cDNA by PCR using appropriate primers (see Supplemental Table 2) containing 5'-BamHI and 3'HindIII (for ETR1 $\left.1_{\mathrm{RD}}\right), 5^{\prime}-\mathrm{NcOl}$ and 3'-BamHI (ETR1 $\left.1_{\mathrm{HK}-\mathrm{RD}}\right)$, and 5'-BamHI and 3'-Eagl (AHK5 $\left.5_{\mathrm{HK}-\mathrm{RD}}\right)$ restriction sites. Amplified ETR1 $1_{R D}$ and $A H K 5_{H K-R D}$ fragments were ligated into $\mathrm{pHYRSF53(Sumo)LA}$ and pFGRSF0 $5^{45}$ (courtesy of Hideo Iwai, University of Helsinki) expression vectors, respectively and the ETR1 $1_{\text {HK-RD fragment into pETM60-Ub2 vector }}^{46}$ (kindly provided by Vladimir V. Rogov, Goethe University Frankfurt). Expression plasmids were transformed into XL10-Gold Ultracompetent Cells (Agilent). DNA was extracted using ZR Plasmid Miniprep - Classic (Zymo Research) and resulting plasmids were verified by sequencing. All mutations listed in Supplemental Table 2 were introduced using the QuikChange Multi Site-Directed Mutagenesis Kit (Agilent) with appropriate mutagenic primers. AHK5 $5_{\mathrm{RD}} \mathrm{D} 828 \mathrm{~A}$ and $\mathrm{AHK} 5_{\mathrm{HK}-\mathrm{RD}} \mathrm{H} 383 \mathrm{~A}$ were generated by one step mutagenesis. To generate the $E T R 1_{R D}$ quintuple mutant, three mutagenesis steps were implemented one after another: i) V711F, ii) G664V, V665L, and iii) E666D, N667G. DNA of ETR1 RD $^{\text {in }}$ pHYRSF53(Sumo)LA vector was used as a template in the first 
mutagenesis step. The mutated DNA from the previous step served as the template in each subsequent one. All introduced mutations were verified by sequencing.

\section{Protein expression and purification}

The lengths and relative molecular weights of proteins used in this study are listed in Supplemental Table 3. AHP proteins were expressed and purified ${ }^{43,44}$ and ETR $1_{\text {HK }}$ protein was obtained as previously described ${ }^{8} . E T R 1_{R D}, E T R 1_{H K-R D}$, and $A H K 5_{H K-R D}$ proteins were prepared as follows: Expression plasmids carrying $\mathrm{ETR} 1_{\mathrm{RD}}$ and $\mathrm{ETR} 1_{\mathrm{HK}-\mathrm{RD}}$ genes were transformed into $E$. coli strain BL21(DE3)pLysS (Novagen, now Merck) and expression plasmid carrying AHK5HK-RD gene into ER2566 (NEB) strain. Cells were cultured with shaking in Terrific broth (TB) medium at pH 7.5 for $3 \mathrm{~h}$ at $37{ }^{\circ} \mathrm{C}$ up to $\mathrm{OD}_{600}$ 0.6-0.8. Protein expression was induced using $1 \mathrm{mM}$ isopropyl $\beta$-D-1thiogalactopyranoside (IPTG) and continued for $5 \mathrm{~h}$ at $37^{\circ} \mathrm{C}$ for ETR $1_{\mathrm{RD}}$ and overnight at $18^{\circ} \mathrm{C}$ for ETR1 $1_{H K-R D}$ and AHK5 $5_{H K-R D}$ proteins. The cells were harvested by centrifugation at $3500 \mathrm{~g}$ for $20 \mathrm{~min}$ at $4{ }^{\circ} \mathrm{C}$. The cell pellet was resuspended in lysis buffer $(50 \mathrm{mM}$ Tris- $\mathrm{HCl}, 0.5 \mathrm{M} \mathrm{NaCl}, 10 \mathrm{mM}$ imidazole,10 \% glycerol, 2.5 mM $\beta$-mercaptoethanol, $0.1 \%$ Triton X-100, pH 7.9) and disrupted by sonication. After centrifugation at $47000 \mathrm{~g}$ for $40 \mathrm{~min}$ at $4{ }^{\circ} \mathrm{C}$, soluble proteins were purified by affinity chromatography using a HisTrap Ni-NTA column (ÄKTA pure FPLC system, GE Healthcare) equilibrated in 50 mM Tris- $\mathrm{HCl}, 0.5 \mathrm{M} \mathrm{NaCl}, 10 \mathrm{mM}$ imidazole, $10 \%$ glycerol, $2.5 \mathrm{mM}$ $\beta$-mercaptoethanol, $\mathrm{pH}$ 7.5. Fusion proteins were eluted using a linear gradient of $0.5 \mathrm{M}$ imidazole in equilibration buffer. Fusion tags were cleaved using S-TEV (Ub-His 6 ) or Ulpl (His6TRX-SMT3) proteases overnight at room temperature while being dialyzed against TEV buffer (50 $\mathrm{mM}$ Tris- $\mathrm{HCl}, 0.5 \mathrm{mM}$ EDTA, $1 \mathrm{mM}$ DTT, $\mathrm{pH} 8$ ) or at $4{ }^{\circ} \mathrm{C}$ while being dialyzed against PBS buffer, respectively. Proteins were purified from their cleaved fusion tags by a second affinity chromatography (using the same column and buffers), followed by size exclusion chromatography using a HiLoad 16/600 Superdex 75 prep-grade column equilibrated with 50 mM Tris- $\mathrm{HCl}, 150 \mathrm{mM} \mathrm{NaCl}, 1 \mathrm{mM}$ EDTA, pH 7.5. Purified proteins were concentrated by ultrafiltration (Amicon Ultra system, Millipore) and stored at $-80{ }^{\circ} \mathrm{C}$. Mutated proteins (ETR $1_{\mathrm{RD}}$ quintuple

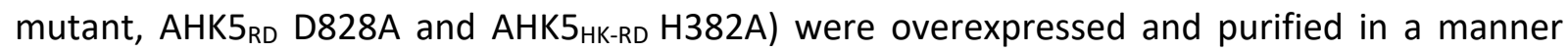
identical to their wild-type versions. $A H K 5_{R D}, C K I 1_{R D}, A H K 4_{R D}$ and $E T R 1_{R D}$ (in pETM60-Ub2) were 
expressed according to a procedure published previously ${ }^{44}$ and purified as ETR $1_{\text {HK-RD }}$ protein using lysis and purification buffers comprising $50 \mathrm{mM}$ Na-phosphate instead of $50 \mathrm{mM}$ Tris.

\section{Kinase assay}

Prior to kinase assay all proteins were suspended in a kinase buffer $(50 \mathrm{mM}$ Tris- $\mathrm{HCl}, 10 \%$ glycerol, $2 \mathrm{mM} \mathrm{DTT}, 5 \mathrm{mM} \mathrm{MnCl}_{2}$ and/or $5 \mathrm{mM} \mathrm{MgCl}_{2}$, $\mathrm{pH}$ 7.5) and the protein concentration was determined by the Bradford protein assay ${ }^{47}$ using bovine serum albumin (Serva) as a standard. The procedure for the kinase assay ${ }^{48}$ was adapted and carried out at room temperature (RT). Autophosphorylation was initiated by adding $1.2 \mu \mathrm{L}\left[\gamma^{32} \mathrm{P}\right]$ ATP $(10 \mu \mathrm{Ci} / \mathrm{mmol}, \mathrm{M} . \mathrm{G} . \mathrm{P})$ to $120 \mu \mathrm{L}$ of $3 \mu \mathrm{M}$ protein and the mixture was incubated for $1 \mathrm{~h}$ at RT. Residual ATP was removed by desalting using Zeba ${ }^{\mathrm{TM}}$ Spin Desalting Columns, $7 \mathrm{~K} \mathrm{MWCO}, 0.5 \mathrm{~mL}$ (ThermoFisher Scientific). Phosphorylated donor proteins were mixed with the phosphate acceptors in a 1:2 (3 $\mu \mathrm{M}: 6 \mu \mathrm{M})$ molar ratio (or ratios of 1:4 and 1:6 for experiments presented in Supplemental Fig. 4). Total reaction volume was $10 \mu \mathrm{L}$, and the reactions were quenched at the times mentioned in the figures by adding 4×SDS-PAGE loading buffer: $0.2 \mathrm{M}$ Tris-HCl, $0.4 \mathrm{M} \mathrm{DTT}, 277 \mathrm{mM}, 8.0 \%$ (w/v) SDS, $6 \mathrm{mM}$ bromophenol blue, 4.3 M glycerol, supplemented with $80 \mathrm{mM}$ EDTA. Phosphorylated proteins were resolved by SDS-PAGE ( $12.5 \%$ gels or otherwise mentioned in the figure legend) without being boiled. Gels were wrapped in plastic foil and used for autoradiography by exposing to Fuji imaging plates. Incorporation of ${ }^{32} \mathrm{P}$ was monitored using Typhoon FLA-7000 Scanner (GE Healthcare) and relative photostimulated luminescence (PSL) signals were quantified using MultiGauge software (FujiFilm). Phosphorylation depletion intensity was calculated by normalizing to the intensity of the band corresponding to autophosphorylated donor at time " 0 " alone $\left(\mathrm{PSL}_{\max }\right)^{49}$.

\section{Statistical analyses of phosphotransfer kinetics}

The decline in the intensity of phosphorylated signals over time was approximated with an inverse model of the form $y=1 /(\alpha+b x)$ as it provided a better fit than a two-parameter exponential function. The comparison of the models for different proteins was performed via Generalized Linear Models with Gamma (GLM-g) error structure ${ }^{50}$. 


\section{NMR spectroscopy}

The ${ }^{15} \mathrm{~N}$-labeled ETR1 $1_{\mathrm{RD}}$ samples were prepared according to a procedure published previously ${ }^{51}$, using M9 minimal medium supplemented with $[15 \mathrm{~N}]-\mathrm{NH}_{4} \mathrm{Cl}$. Cells (E. coli ER2566 carrying pHYRSF53(Sumo)LA vector with ETR1 $1_{\text {RD }}$ gene) were harvested after overnight expression in $22^{\circ} \mathrm{C}$ and purified as described above. Samples of $600 \mu \mathrm{L}$ comprising $0.5 \mathrm{mM}{ }^{15} \mathrm{~N}$-labeled ETR1 $1_{\mathrm{RD}}$ in 50 mM Na-phosphate- $\mathrm{HCl}$ buffer $\mathrm{pH}$ 7.5, containing $150 \mathrm{mM} \mathrm{NaCl}, 1 \mathrm{mM}$ DTT, 1 mM EDTA and $10 \%$ deuterium oxide were used. Titrations with $\mathrm{MgCl}_{2}$ (steps of $0.25 \mathrm{mM}, 0.5 \mathrm{mM}, 0.75 \mathrm{mM}, 1 \mathrm{mM}$, $1.25 \mathrm{mM}, 1.5 \mathrm{mM}, 1.75 \mathrm{mM}, 2 \mathrm{mM}, 3 \mathrm{mM}, 4 \mathrm{mM}, 5 \mathrm{mM}, 8 \mathrm{mM}, 10 \mathrm{mM}, 30 \mathrm{mM}, 50 \mathrm{mM})$ and $\mathrm{MnCl}_{2}$ (steps of $0.1 \mathrm{mM}, 0.2 \mathrm{mM}, 0.3 \mathrm{mM}, 0.4 \mathrm{mM}, 0.6 \mathrm{mM}, 0.9 \mathrm{mM}, 2 \mathrm{mM}, 3 \mathrm{mM}, 5 \mathrm{mM}, 10$ $\mathrm{mM}$ ) were performed. Each titration step was measured as ${ }^{1} \mathrm{H}-{ }^{15} \mathrm{~N} \mathrm{HSQC}$ spectra. NMR spectra of $\mathrm{MnCl}_{2}$ titrations were acquired at $25{ }^{\circ} \mathrm{C}$ using a Bruker Avance III HD $600 \mathrm{MHz}$ spectrometer, equipped with the cryogenic $\left({ }^{1} \mathrm{H}_{-}{ }^{31} \mathrm{P}_{-}{ }^{13} \mathrm{C}_{-}{ }^{15} \mathrm{~N}\right)$ inverse probe-head (Bruker) and $\mathrm{MnCl}_{2}$ titrations using a Bruker Avance III HD950 MHz spectrometer equipped with the cryogenic $\left({ }^{1} \mathrm{H}-{ }^{13} \mathrm{C}-{ }^{15} \mathrm{~N}\right)$ inverse probe-head.

\section{Microscale thermophoresis (MST) for protein-protein interaction analysis}

To perform the MST experiment, purified $A H K 5_{R D}$ as a target was labelled with Alexa Fluor-488 (Thermo Fisher Scientific) according to the manufacturer's instructions. The protein $\left(20 \mathrm{mg} \cdot \mathrm{mL}^{-1}\right.$ in $50 \mathrm{mM}$ HEPES, $300 \mathrm{mM} \mathrm{NaCl}, 5 \%$ glycerol, pH 7.8) was mixed with 4 times the molar amount of Alexa Fluor-488 dye dissolved in $1 / 10$ final volume of freshly prepared $1 \mathrm{M} \mathrm{NaHCO}_{3}$ and stirred for $1 \mathrm{~h}$ at RT in darkness. The unbound dye was removed by ultrafiltration (Amicon Ultra system, Millipore) and the concentration of protein as well as the degree of labelling was checked. Fluorescently labelled $A H K 5_{\mathrm{RD}}$ was kept constant at $92 \mathrm{nM}$ in all MST measurements. ETR1 $1_{\mathrm{HK}}$ and

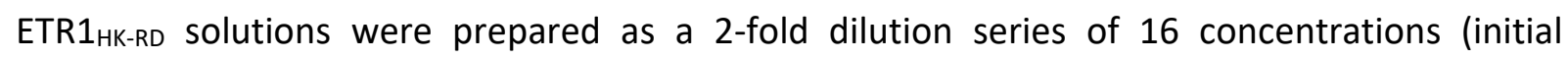
concentration of ETR1 $1_{\mathrm{HK}}$ was $315 \mu \mathrm{M}$ and that of ETR1 $1_{\mathrm{HK}-\mathrm{RD}}$ was $261 \mu \mathrm{M}$ ) in MST buffer containing $50 \mathrm{mM}$ HEPES pH 7.8, $300 \mathrm{mM} \mathrm{NaCl}, 5$ \% glycerol and 0.015 \% Fos-choline 16. Each reaction mixture was incubated for $10 \mathrm{~min}$ in a PCR-tube followed by thermophoresis in standard MSTgrade glass capillaries in a Monolith NT.115 instrument (Nanotemper Technologies). 
Measurements were performed under the blue fluorescence channel, with medium MST power, excitation power $80 \%$ and constant $25{ }^{\circ} \mathrm{C}$ temperature. All results are averages of three independent repetitions.

\section{Fluorescent anisotropy assay}

The assay was performed using a Fluoromax 4 spectrofluorometer (HORIBA, Jobin Yvon). Purified $A H K 5_{R D}$ protein was labeled with fluorescent Alexa-Fluor 484 . The titration of $1 \mathrm{mM} \mathrm{ETR} 1_{\mathrm{HK}}$

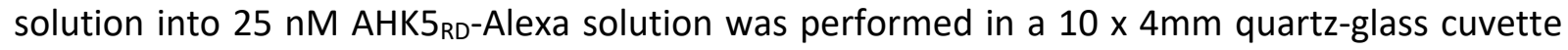
with a chamber for a magnetic bar stirrer at $25^{\circ} \mathrm{C}$. The interaction buffer was $50 \mathrm{mM}$ HEPES, 200 $\mathrm{mM} \mathrm{NaCl}, 5 \mathrm{mM} \mathrm{MgCl}$, $5 \mathrm{mM} \mathrm{ATP}, 0.05 \%$ Tween, $\mathrm{pH}$ 7.5. All tests were repeated three times and averaged for each data point. The excitation wavelength was $492 \mathrm{~nm}$ and emission was monitored at $520 \mathrm{~nm}$ with a slit width of $5 \mathrm{~nm}$. Integration time was $1 \mathrm{~s}$. A cuvette was equilibrated with buffer containing labelled protein $10 \mathrm{~min}$ before each titration experiment by stirring (speed 5). Before each measurement point the sample was equilibrated in the cuvette with the ligand for 30 seconds. As a negative control the same measurement was performed adding buffer (as titrant) to $A H K 5_{R D}$ in the cuvette in the same volumes as $E T R 1_{H K}$ solution.

\section{In planta analyses}

For in planta analyses, Arabidopsis thaliana wild-type (Col-0, N1092) and the ahk5-1 mutant (N802391, SAIL_50_H11) were used. The seedlings were grown on vertically oriented plates with $1 / 2$ strength Murashige and Skoog (MS) medium containing $1 \%$ sucrose in growth chambers (CLF Plant Climatics, GmbH). Six-day-old (6 DAG) seedlings were treated in liquid MS medium containing $5 \mu \mathrm{M}$ benzylaminopurine (BAP, Duchefa), $5 \mu \mathrm{M}$ 1-aminocyclopropane-1-carboxylic acid (ACC, Sigma), $5 \mu \mathrm{M}$ BAP $+5 \mu \mathrm{M}$ ACC, $1 \mu \mathrm{M}$ aminoethoxyvinylglycine (AVG, Sigma) or $0.1 \%$ DMSO as control (mock) for $24 \mathrm{~h}$ prior to imaging and image processing for spatial-specific analyses of fluorescent reporter line pTCSn::GFP-ER (in Col- $0^{52}$ and ahk5-1 background) and columella cell count using ZEN blue (Carl Zeiss Microscopy, GmbH). $2 \mu \mathrm{L} \cdot \mathrm{L}^{-1}$ 1methylcyclopropene (1-MCP) was added to block ethylene signaling and the expression patterns of pTCSn::GFP-ER. 1-MCP was incorporated with air flow controlled by a gas mixing system (GMS; 
Photon System Instruments) inside closed chambers and air was used as control. For fluorescence visualization, roots were stained with PI and visualized using a ZEISS LSM780/880 confocal microscope. Quantification of reporter gene expression was described previously ${ }^{52}$ with slight modifications (see Fig. 4 and Supplemental Figure S10). At least 10 seedlings were evaluated in three independent experiments.

401

402

403

404

405

406

407

408

409

410

411

412

413

To monitor the number of detached root cap cell layers, five-day-old (5 DAG) seedlings were transferred to MS medium with or without $1 \mu \mathrm{M}$ 1-aminocyclopropane-1-carboxylic acid, and grown on vertically oriented plates for five more days prior to imaging with the Axiolab 5 (Carl Zeiss Microscopy, GmbH). To determine the AHK5-dependent ethylene effect on the root cap, attached and detached columella, columella cell count analysis was done on ahk5-1 and compared to that in Col-0 by counting the columella cell layers from the outermost root cap until the first differentiated columella cell layer and the detached root cap layers ${ }^{13}$. At least 15 seedlings were evaluated in three independent experiments.

The 6 DAG seedlings grown directly on +/- 1 MM ACC supplemented MS media was employed for root length, proximal meristem (PM) and transition zone (TZ) analysis. The root length was evaluated by tools of Figi. The size of PM and TZ was determined as a number of cortex cells filed from QC to the first elongated cell. Before imaging (LSM 800) the roots were fixed and stained with Schiff reagent and propidium iodide mixture. The length of the cortex cells was measured and evaluated via Cell-o-Tape plugin in Fiji ${ }^{33}$. The differences of cell length indicated borders of the PM, TZ and elongation zone. In statistics, changepoint detection is used to identify possible changes in a series of data. These changes may refer to mean, variance, trend, or other stochastic - statistical properties. In this work, an iterative Bayesian changepoint detection method is applied to identify significant changepoints in the mean root cells length as the cortex cells grow $^{54}$. This method can be of great assistance in identifying root cell zones as it is effective when not too many changes occur and they are of a reasonable size ${ }^{54}$. The changepoint detection was implemented in R environment (v. 3.6.0) using the package "bcp"55,56.

Based on convention, all critical values are at $\alpha=0.05$. At least 15 seedlings were evaluated in three independent experiments. 


\section{FLIM-FRET}

All clones for FLIM-FRET experiments were constructed using Gateway ${ }^{\mathrm{TM}}$ technology (Invitrogen). The entry clones were obtained via BP-reaction in pDONR207. The binary vectors for expression of the GFP/RFP fusion proteins under the control of 35 S promoter were constructed via LRreaction using the corresponding entry clones and the destination vector pH7FWG2 for the $\triangle T M$ ETR1 construct with C-terminal GFP, or pB7WGR2 for the AHK5 construct with N-terminal RFP and PB7RWG2 for the AHK5 construct with C-terminal RFP ${ }^{57}$. Primers used for cloning are in supplemental table S1. Construct preparation and tobacco infiltration procedures were identical to those described ${ }^{58}$. Gene silencing in Nicotiana benthamiana was suppressed by co-infiltrating the p19 protein from tomato bushy stunt virus cloned into pBIN6159. FLIM-FRET data were acquired using a laser scanning confocal imaging microscope Zeiss LSM 780 AxioObserver equipped with an external In Tune laser $(488-640 \mathrm{~nm},<3 \mathrm{~nm}$ pulse width, pulsed at $40 \mathrm{MHz}, 1.5 \mathrm{~mW}$ ), C-Apochromat $40 \mathrm{x}$ water objective (NA 1.2) and the HPM-100-40 Hybrid Detector from Becker and Hickl GmbH. PMT detectors were used for acquiring confocal images using the same instrument. Photon counting was done using Simple-Tau 150N (Compact TCSPC system based on SPC-150N) with DCC-100 detector controller. GFP and RFP were excited at 490 $\mathrm{nm}$ wavelength from the In Tune laser and at $561 \mathrm{~nm}$ from DPSS-laser respectively, with appropriate laser power and PMT gain to capture confocal images of the donor and acceptor. Confocal images were processed in Zen 2.3 light version from Zeiss. After acquiring confocal images, the same cell was excited with only $490 \mathrm{~nm}$ In Tune laser with appropriate laser power to avoid any pile up effect, and the detector was changed to HPM100-40 to obtain FLIM data. Acquisition of FLIM data was done in SPCM 64 version 9.8 and SPCImage version 7.3 from Becker and Hickl GmbH was used for data analysis. To avoid background signal from chloroplasts, selected regions of interest (ROIs) containing signal in the corresponding confocal images were used for fluorescent lifetime calculation. A multiexponential decay model was used for fitting. In most cases two or three component fitting was applied to get the least $\chi^{2}$ parameter because of the background from the leaf specimen. Lifetime components with very low values below $500 \mathrm{~ns}$ 
were considered as background contribution and avoided for average lifetime calculations. FRET efficiencies were calculated using the equation

$$
E=1-\tau_{D A} / \tau_{D}
$$

where $E$ is energy transfer efficiency, $\tau_{D A}$ is donor fluorescent lifetime in the presence of acceptor and $\tau_{D}$ is the donor fluorescent lifetime in the absence of acceptor. Student's t-test was used to evaluate the significant difference in the average lifetime between different groups.

\section{Protein crystallization}

Initial crystallization conditions were obtained from the literature ${ }^{51}$. The conditions were further optimized by varying the temperature, the crystallization technique, and the presence of additives. For crystallization, the proteins were dissolved in 25 mM HEPES, 1 mM DTT, pH 7.5. Well-diffracting crystals were obtained using hanging drop vapor diffusion with $20 \mathrm{mg} \cdot \mathrm{mL}^{-1}$ ETR1 $1_{\mathrm{RD}}\left(15 \mathrm{mg} \cdot \mathrm{mL}^{-1}\right.$ for the ETR1 $1_{\mathrm{RD}}$ mutant) with $1.5 \mathrm{M} \mathrm{Li}_{2} \mathrm{SO}_{4}, 0.1 \mathrm{M} \mathrm{HEPES}, \mathrm{pH} 7.5$ as a precipitant. The drops were prepared by mixing the protein and the precipitant in volumes of 1.5:1.5 $\mu \mathrm{l}, 1.5: 3 \mu \mathrm{l}$ and 3:1.5 $\mu \mathrm{l}$. For the ETR $1_{\mathrm{RD}} \mathrm{WT}, 0.1 \mathrm{M}$ EDTA $(0.5 \mu \mathrm{L})$ was added to each drop as an additive. The drops were equilibrated at $17^{\circ} \mathrm{C}$ over a $1 \mathrm{ml}$ reservoir of the precipitant. All crystals were cryo-protected in $30 \%$ pentaerythritol ethoxylate and frozen in liquid nitrogen. Diffraction data were collected at $100 \mathrm{~K}$ at the BESSY II synchrotron (Helmholtz-Zentrum Berlin, Germany) $^{60}$, beamlines 14.3 (crystals of wild-type ETR1 $1_{\mathrm{RD}}$ ) and 14.2 (ETR1 $1_{\mathrm{RD}} \mathrm{G664V}, \mathrm{V} 665 \mathrm{~L}$, E666N, D667G, V711F).

\section{Structure determination}

Diffraction images were processed using $\mathrm{XDS}^{61}$ or XDSAPP ${ }^{62}$ programs and converted to structure factors using the program Scala from package CCP4 v.7.063 with $5 \%$ of the data reserved for $R_{\text {free }}$ calculation. The structures of the complexes were solved by molecular replacement with Phaser ${ }^{64}$ (ETR1 $_{\text {RD }}$ G664V, V665L, E666D, N667G, V711F) or MOLREP65 (ETR1 $1_{\text {RD }}$ WT), respectively. The ETR1 $1_{\mathrm{RD}}$ structure (PDB ID: 1DCF) was used as the initial coordinates for replacement. Refinement of the molecules was performed using REFMAC5 ${ }^{66}$ alternated with manual model building in Coot v. $0.8^{66,67}$. Water molecules were added by Coot and checked manually. The addition of 
alternative conformations, where necessary, resulted in final structures that were validated using the MolProbity ${ }^{68}$ (http://molprobity.biochem.duke.edu) validation server, and were deposited in the PDB database as 7PN2 and 7PN3 for the ETR1 ${ }_{R D}$ WT and ETR1 $1_{R D}$ G664V, V665L, E666D, N667G, V711F, respectively; molecular drawings were prepared using Pymol (Schrödinger, Inc.).

\section{References}

1 Street, I. H. et al. Ethylene Inhibits Cell Proliferation of the Arabidopsis Root Meristem. Plant Physiology, doi:10.1104/pp.15.00415 (2015).

2 Zdarska, M. et al. ETR1 Integrates Response to Ethylene and Cytokinins into a Single Multistep Phosphorelay Pathway to Control Root Growth. Mol Plant 12, 1338-1352, doi:10.1016/j.molp.2019.05.012 (2019).

3 Mira-Rodado, V. New Insights into Multistep-Phosphorelay (MSP)/ Two-Component System (TCS) Regulation: Are Plants and Bacteria that Different? Plants (Basel) 8, doi:10.3390/plants8120590 (2019).

$4 \quad$ Hung, Y. L., Jiang, I., Lee, Y. Z., Wen, C. K. \& Sue, S. C. NMR Study Reveals the Receiver Domain of Arabidopsis ETHYLENE RESPONSE1 Ethylene Receptor as an Atypical Type Response Regulator. PLoS One 11, e0160598, doi:10.1371/journal.pone.0160598 (2016).

5 Otrusinova, O. et al. Conformational dynamics are a key factor in signaling mediated by the receiver domain of a sensor histidine kinase from Arabidopsis thaliana. J Biol Chem 292, 17525-17540, doi:10.1074/jbc.M117.790212 (2017).

6 Pekarova, B. et al. Structure and binding specificity of the receiver domain of sensor histidine kinase CKI1 from Arabidopsis thaliana. Plant J 67, 827-839, doi:10.1111/j.1365313X.2011.04637.x (2011).

7 Gao, R. \& Stock, A. M. Quantitative Analysis of Intracellular Response Regulator Phosphatase Activity of Histidine Kinases. Methods Enzymol 607, 301-319, doi:10.1016/bs.mie.2018.04.004 (2018).

8 Otrusinova, O. et al. Conformational dynamics as a key factor of signaling mediated by the receiver domain of sensor histidine kinase from Arabidopsis thaliana. J Biol Chem, doi:10.1074/jbc.M117.790212 (2017).

9 Muller-Dieckmann, H. J., Grantz, A. A. \& Kim, S. H. The structure of the signal receiver domain of the Arabidopsis thaliana ethylene receptor ETR1. Structure 7, 1547-1556 (1999).

10 Bauer, J. et al. Structure-Function Analysis of Arabidopsis thaliana Histidine Kinase AHK5 Bound to Its Cognate Phosphotransfer Protein AHP1. Mol Plant 6, 959-970, doi:sss126 [pii]

$10.1093 / \mathrm{mp} / \mathrm{sss} 126$ (2013).

11 Zurcher, E. et al. A robust and sensitive synthetic sensor to monitor the transcriptional output of the cytokinin signaling network in planta. Plant Physiology 161, 1066-1075, doi:10.1104/pp.112.211763 (2013). 
12 Hall, A. E., Findell, J. L., Schaller, G. E., Sisler, E. C. \& Bleecker, A. B. Ethylene perception by the ERS1 protein in Arabidopsis. Plant Physiology 123, 1449-1458 (2000).

13 Ortega-Martinez, O., Pernas, M., Carol, R. J. \& Dolan, L. Ethylene modulates stem cell division in the Arabidopsis thaliana root. Science 317, 507-510, doi:317/5837/507 [pii]

10.1126/science.1143409 (2007).

14 Vicre, M., Santaella, C., Blanchet, S., Gateau, A. \& Driouich, A. Root border-like cells of Arabidopsis. Microscopical characterization and role in the interaction with rhizobacteria. Plant Physiol 138, 998-1008, doi:10.1104/pp.104.051813 (2005).

15 Ponce, G., Barlow, P. W., Feldman, L. J. \& Cassab, G. I. Auxin and ethylene interactions control mitotic activity of the quiescent centre, root cap size, and pattern of cap cell differentiation in maize. Plant Cell Environ 28, 719-732, doi:10.1111/j.13653040.2005.01318.x (2005).

16 Dubreuil, C., Jin, X., Gronlund, A. \& Fischer, U. A Local Auxin Gradient Regulates Root Cap Self-Renewal and Size Homeostasis. Curr Biol 28, 2581-2587 e2583, doi:10.1016/j.cub.2018.05.090 (2018).

17 Takatsuka, H., Higaki, T. \& Umeda, M. Actin Reorganization Triggers Rapid Cell Elongation in Roots. Plant Physio/ 178, 1130-1141, doi:10.1104/pp.18.00557 (2018).

18 Goodman, A. L. et al. Direct interaction between sensor kinase proteins mediates acute and chronic disease phenotypes in a bacterial pathogen. Genes Dev 23, 249-259, doi:10.1101/gad.1739009 (2009).

19 Francis, V. I. et al. Multiple communication mechanisms between sensor kinases are crucial for virulence in Pseudomonas aeruginosa. Nat Commun 9, 2219, doi:10.1038/s41467-018-04640-8 (2018).

20 Mancl, J. M., Ray, W. K., Helm, R. F. \& Schubot, F. D. Helix Cracking Regulates the Critical Interaction between RetS and GacS in Pseudomonas aeruginosa. Structure 27, 785-793 e785, doi:10.1016/j.str.2019.02.006 (2019).

21 Zhao, H. et al. Histidine kinase MHZ1/OsHK1 interacts with ethylene receptors to regulate root growth in rice. Nat Commun 11, 518, doi:10.1038/s41467-020-14313-0 (2020).

22 Casino, P., Rubio, V. \& Marina, A. Structural insight into partner specificity and phosphoryl transfer in two-component signal transduction. Cell 139, 325-336, doi:S00928674(09)01102-7 [pii]

10.1016/j.cell.2009.08.032 (2009).

23 Schaller, G. E. \& Bleecker, A. B. Ethylene-binding sites generated in yeast expressing the Arabidopsis ETR1 gene. Science 270, 1809-1811 (1995).

24 Hass, C. et al. The response regulator 2 mediates ethylene signalling and hormone signal integration in Arabidopsis. EMBO J 23, 3290-3302, doi:10.1038/sj.emboj.7600337

7600337 [pii] (2004).

25 Desikan, R. et al. The histidine kinase AHK5 integrates endogenous and environmental signals in Arabidopsis guard cells. PLoS One 3, e2491, doi:10.1371/journal.pone.0002491 (2008). 
26 Desikan, R. et al. Ethylene-induced stomatal closure in Arabidopsis occurs via AtrbohFmediated hydrogen peroxide synthesis. The Plant journal : for cell and molecular biology 47, 907-916, doi:10.1111/j.1365-313X.2006.02842.x (2006).

27 Mira-Rodado, V. et al. Identification of two-component system elements downstream of AHK5 in the stomatal closure response of Arabidopsis thaliana. Plant Signal Behav 7, 1467-1476, doi:10.4161/psb.21898 (2012).

28 Dortay, H. et al. Toward an interaction map of the two-component signaling pathway of Arabidopsis thaliana. J Proteome Res 7, 3649-3660, doi:10.1021/pr0703831 (2008).

29 Dortay, H., Mehnert, N., Burkle, L., Schmulling, T. \& Heyl, A. Analysis of protein interactions within the cytokinin-signaling pathway of Arabidopsis thaliana. FEBS $J \mathbf{2 7 3}$, 4631-4644, doi:EJB5467 [pii]

10.1111/j.1742-4658.2006.05467.x (2006).

30 Iwama, A. et al. AHK5 histidine kinase regulates root elongation through an ETR1dependent abscisic acid and ethylene signaling pathway in Arabidopsis thaliana. Plant Cell Physiol 48, 375-380, doi:pcl065 [pii]

10.1093/pcp/pcl065 (2007).

31 Driouich, A., Durand, C. \& Vicre-Gibouin, M. Formation and separation of root border cells. Trends Plant Sci 12, 14-19, doi:10.1016/j.tplants.2006.11.003 (2007).

32 Hawes, M. C., Bengough, G., Cassab, G. \& Ponce, G. Root Caps and Rhizosphere. Journal of Plant Growth Regulation 21, 352-367, doi:10.1007/s00344-002-0035-y (2002).

33 Bengough, A. G. \& McKenzie, B. M. Sloughing of root cap cells decreases the frictional resistance to maize (Zea mays L) root growth. Journal of Experimental Botany 48, 885893, doi:DOI 10.1093/jxb/48.4.885 (1997).

34 Pandey, B. K. et al. Plant roots sense soil compaction through restricted ethylene diffusion. Science 371, 276-280, doi:10.1126/science.abf3013 (2021).

35 Stepanova, A. N. et al. TAA1-mediated auxin biosynthesis is essential for hormone crosstalk and plant development. Cell 133, 177-191, doi:S0092-8674(08)00212-2 [pii]

10.1016/j.cell.2008.01.047 (2008).

36 Ruzicka, K. et al. Cytokinin regulates root meristem activity via modulation of the polar auxin transport. Proc Natl Acad Sci U S A 106, 4284-4289, doi:0900060106 [pii]

10.1073/pnas.0900060106 (2009).

37 Swarup, R. et al. Ethylene upregulates auxin biosynthesis in Arabidopsis seedlings to enhance inhibition of root cell elongation. Plant Cell 19, 2186-2196, doi:tpc.107.052100 [pii]

10.1105/tpc.107.052100 (2007).

38 Vaseva, II et al. The plant hormone ethylene restricts Arabidopsis growth via the epidermis. Proc Natl Acad Sci U S A 115, E4130-E4139, doi:10.1073/pnas.1717649115 (2018).

39 Di Mambro, R. et al. The Lateral Root Cap Acts as an Auxin Sink that Controls Meristem Size. Curr Biol 29, 1199-1205 e1194, doi:10.1016/j.cub.2019.02.022 (2019). 
40 Schultz, J., Milpetz, F., Bork, P. \& Ponting, C. P. SMART, a simple modular architecture research tool: identification of signaling domains. Proc Natl Acad Sci U S A 95, 5857-5864 (1998).

41 Sievers, F. et al. Fast, scalable generation of high-quality protein multiple sequence alignments using Clustal Omega. Mol Syst Biol 7, 539, doi:10.1038/msb.2011.75 (2011).

42 Kumar, S., Stecher, G. \& Tamura, K. MEGA7: Molecular Evolutionary Genetics Analysis Version 7.0 for Bigger Datasets. Mol Biol Evol 33, 1870-1874, doi:10.1093/molbev/msw054 (2016).

43 Degtjarik, O. et al. Cloning, expression, purification, crystallization and preliminary X-ray diffraction analysis of AHP2, a signal transmitter protein from Arabidopsis thaliana. Acta Crystallogr Sect F Struct Biol Cryst Commun 69, 158-161, doi:S174430911205186X [pii]

\subsection{7/S174430911205186X (2013).}

44 Borkovcova, P. et al. Antibodies against CKI1RD, a receiver domain of the sensor histidine kinase in Arabidopsis thaliana: from antigen preparation to in planta immunolocalization. Phytochemistry 100, 6-15, doi:10.1016/j.phytochem.2014.01.007 (2014).

45 Guerrero, F., Ciragan, A. \& Iwai, H. Tandem SUMO fusion vectors for improving soluble protein expression and purification. Protein Expr Purif 116, 42-49, doi:10.1016/j.pep.2015.08.019 (2015).

46 Rogov, V. V. et al. A universal expression tag for structural and functional studies of proteins. Chembiochem 13, 959-963, doi:10.1002/cbic.201200045 (2012).

47 Zhou, Z. Y. et al. Functional characterization of the CKRC1/TAA1 gene and dissection of hormonal actions in the Arabidopsis root. Plant $J$ 66, 516-527, doi:10.1111/j.1365313X.2011.04509.x (2011).

48 Ruszkowski, M. et al. Medicago truncatula histidine-containing phosphotransfer protein: structural and biochemical insights into the cytokinin transduction pathway in plants. FEBS J 280, 3709-3720, doi:10.1111/febs.12363 (2013).

49 Barbieri, C. M., Mack, T. R., Robinson, V. L., Miller, M. T. \& Stock, A. M. Regulation of response regulator autophosphorylation through interdomain contacts. J Biol Chem 285, 32325-32335, doi:M110.157164 [pii]

10.1074/jbc.M110.157164 (2010).

50 Pekar, S. \& Brabec, M. 1 online resource (247 pages) (Masaryk University,, Brno, Czech Republic, 2016).

51 Grantz, A. A., Muller-Dieckmann, H. J. \& Kim, S. H. Subcloning, crystallization and preliminary X-ray analysis of the signal receiver domain of ETR1, an ethylene receptor from Arabidopsis thaliana. Acta Crystallogr D Biol Crystallogr 54, 690-692 (1998).

52 Zdarska, M. et al. ETR1 Integrates Response to Ethylene and Cytokinins into a Single Multistep Phosphorelay Pathway to Control Root Growth. Mol Plant, doi:10.1016/j.molp.2019.05.012 (2019).

53 French, A. P. et al. Identifying biological landmarks using a novel cell measuring image analysis tool: Cell-o-Tape. Plant Methods 8, 7, doi:10.1186/1746-4811-8-7 (2012).

54 Barry, D. \& Hartigan, J. A. A Bayesian-Analysis for Change Point Problems. Journal of the American Statistical Association 88, 309-319, doi:Doi 10.1080/01621459.1993.10594323 (1993). 
55 Erdman, C. \& Emerson, J. W. bcp: An R package for performing a Bayesian analysis of change point problems. J Stat Softw 23, 1-13 (2007).

56 R_Core_Team. R: A language and environment for statistical computing. . R Foundation for Statistical Computing, Vienna, Austria. URL: https://www.R-project.org/(2021).

57 Karimi, M., Depicker, A. \& Hilson, P. Recombinational cloning with plant gateway vectors. Plant Physiol 145, 1144-1154, doi:10.1104/pp.107.106989 (2007).

58 Horak, J. et al. The Arabidopsis thaliana response regulator ARR22 is a putative AHP phospho-histidine phosphatase expressed in the chalaza of developing seeds. BMC Plant Biol 8, 77, doi:1471-2229-8-77 [pii]

10.1186/1471-2229-8-77 (2008).

59 Voinnet, O., Lederer, C. \& Baulcombe, D. C. A Viral Movement Protein Prevents Spread of the Gene Silencing Signal in Nicotiana benthamiana. Cell 103, 157-167 (2000).

60 Energie., H.-Z. B. f. M. u. The MX beamlines BL14.1-3 at BESSY II. . Journal of large-scale research facilities 2, doi:http://dx.doi.org/10.17815/ilsrf-2-64 (2016).

61 Kabsch, W. Xds. Acta Crystallogr D Biol Crystallogr 66, 125-132, doi:10.1107/S0907444909047337 (2010).

62 Sparta, K. M., Krug, M., Heinemann, U., Mueller, U. \& Weiss, M. S. Xdsapp2.0. J Appl Crystallogr 49, 1085-1092, doi:10.1107/S1600576716004416 (2016).

63 Winn, M. D. et al. Overview of the CCP4 suite and current developments. Acta Crystallogr D Biol Crystallogr 67, 235-242, doi:10.1107/S0907444910045749 (2011).

64 McCoy, A. J. et al. Phaser crystallographic software. J Appl Crystallogr 40, 658-674, doi:10.1107/S0021889807021206 (2007).

65 Vagin, A. \& Teplyakov, A. Molecular replacement with MOLREP. Acta Crystallogr D Biol Crystallogr 66, 22-25, doi:10.1107/S0907444909042589 (2010).

66 Skubak, P., Murshudov, G. N. \& Pannu, N. S. Direct incorporation of experimental phase information in model refinement. Acta Crystallogr D Biol Crystallogr 60, 2196-2201, doi:10.1107/S0907444904019079 (2004).

67 Emsley, P., Lohkamp, B., Scott, W. G. \& Cowtan, K. Features and development of Coot. Acta Crystallogr D Biol Crystallogr 66, 486-501, doi:10.1107/S0907444910007493 (2010).

68 Williams, C. J. et al. MolProbity: More and better reference data for improved all-atom structure validation. Protein Sci 27, 293-315, doi:10.1002/pro.3330 (2018).

69 Bauer, J. et al. Structure-Function Analysis of Arabidopsis thaliana Histidine Kinase AHK5 Bound to Its Cognate Phosphotransfer Protein AHP1. Molecular Plant 6, 959-970, doi:10.1093/mp/sss126 (2013).

\section{Acknowledgements}

We thank Prof. Stano Pekar (Masaryk University, Brno, Czech Republic) for statistical calculations. The work was supported by the Czech Science Foundation (19-24753S and 19-23108Y) and the Ministry of Education, Youth and Sports of the Czech Republic under the projects CZ.02.1.01/0.0/0.0/16_026/0008446, LTAUSA18161 and LTC19047. E.U. and E.Z. were supported 
683

684

685

686

687

688

689

690

691

692

693

694

695

696

697

698

699

700

701

702

703

704

705

706

707

708

709

710

711

by the Russian Science Foundation (20-14-00140). We acknowledge the Biomolecular Interactions and Crystallization Core Facility of CEITEC MU supported by the CIISB research infrastructure (LM2018127 funded by MEYS CR), the Proteomics Core Facility of CEITEC MU, the Plant Sciences Core Facility of CEITEC MU and the Josef Dadok National NMR Centre for their support in gathering the scientific data presented in this paper. We thank HZB for the allocation of synchrotron radiation beamtime. Part of this research was carried out at the light source PETRA III at DESY, a member of the Helmholtz Association (HGF). We acknowledge the core facility CELLIM of CEITEC supported by the Czech-Biolmaging large RI project (LM2015062 funded by MEYS CR) for their support in gathering the scientific data presented in this paper.

\section{Author contributions}

B.P. and Ja.H. conceived the research; A.S., A.R.C., B.P., M.Z., J.K., Z.J., A.J., M.H., and E.U. performed the research; A.S., A.R.C., B.P., M.Z., Jo.H., A.J., I.S., K.H., E.Z., L.Z., M.W., M.T., V.M. and Ja.H. analyzed the data; A.S., A.R.C., B.P., M.Z., A.J., E.Z., Jo.H., L.Z. and Ja.H. wrote the paper.

\section{Competing interests}

The authors declare that they have no competing interests

\section{Supplemental Material}

Fig. 1. ETR1 $1_{R D}$ is unable to mediate phosphotransfer in ETR1-mediated MSP signaling.

Fig. 2. Phylogenetic analysis of Arabidopsis RDs.

Fig. 3. Multiple sequence alignment of ETR $1_{R D}$ and RDs from histidine kinases in Arabidopsis thaliana.

Fig. 4. ETR1 $1_{\text {HK }}$ phosphorylates RDs of a different sensor HK.

Fig. 5. Kinetics of phosphotransfer from ETR1 $1_{\mathrm{HK}}$ to $\mathrm{CKI} 1_{\mathrm{RD}}$.

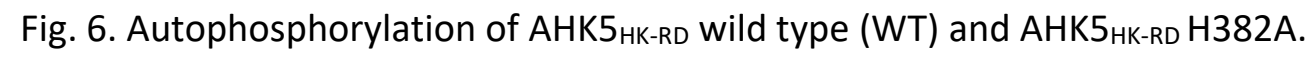

Fig. 7. Mutant ETR $1_{R D}$ with a $\beta 3-\alpha 3$ loop rewired to resemble that of $A H K 5_{R D}$ is not able to accept phosphate from ETR1 $1_{\text {HK. }}$

Fig. 8. ETR1 $1_{\mathrm{HK}}$ interacts with $\mathrm{AHK} 5_{\mathrm{RD}}$ in vitro. 
712 Fig. 9. Full-length ETR1 and AHK5 interact in vivo.

713 Fig.10. AVG dilution series treatments with $p T C S n:: G F P$-ER, representative ROI selection used for 714 signal quantification and analysis of columella cell layers and root length.

715 Table S1. Data collection and refinement statistics for ETR1 $1_{\mathrm{RD}}$ proteins. Values in parentheses 716 correspond to the highest resolution shell.

717 Table S2. Primer sequences used for cloning and mutagenesis. Restriction sites are underlined.

718 Table S3. List of proteins used. 
A

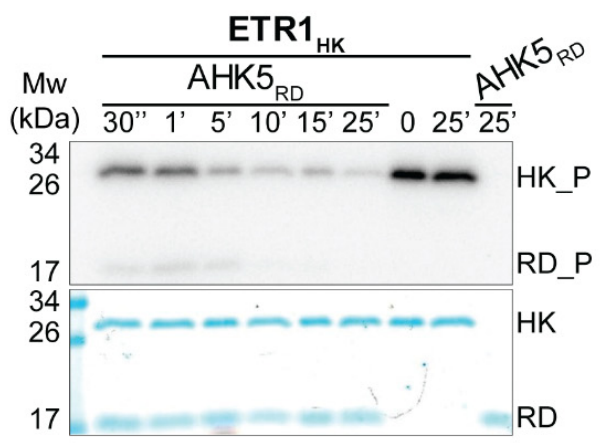

C

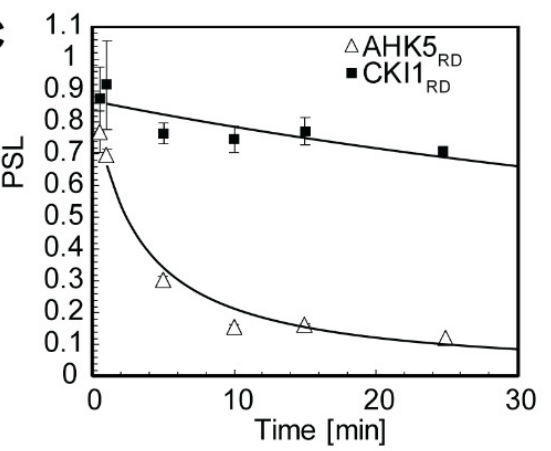

$\mathbf{E}$

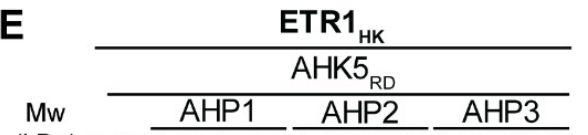

(kDa) 0 10, 010 "30"10' 010 "30"10'0 10"30"10'

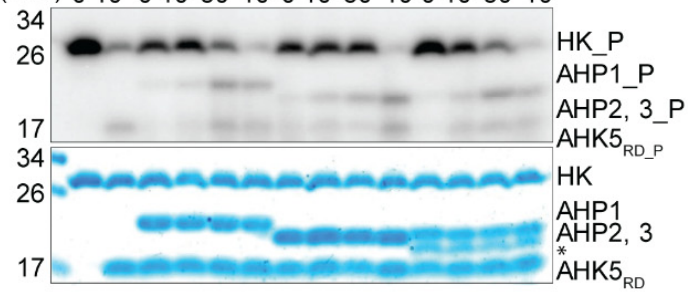

G

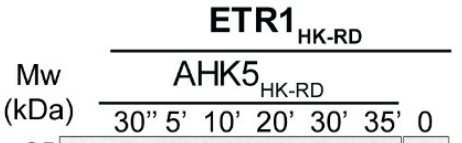

(kDa) 30" 5' 10'20'30'35'0

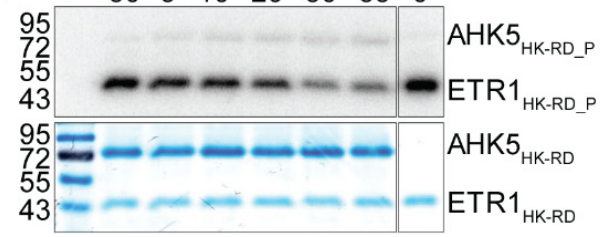

B

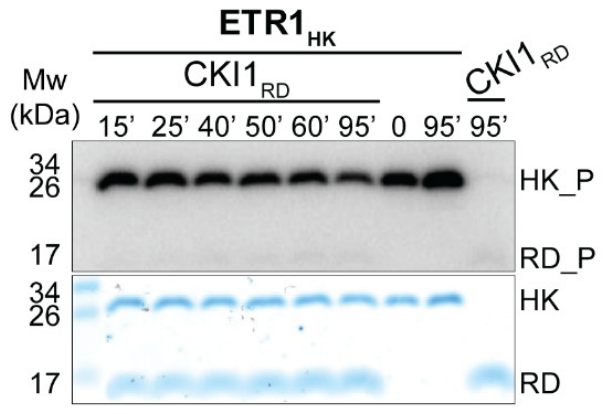

D

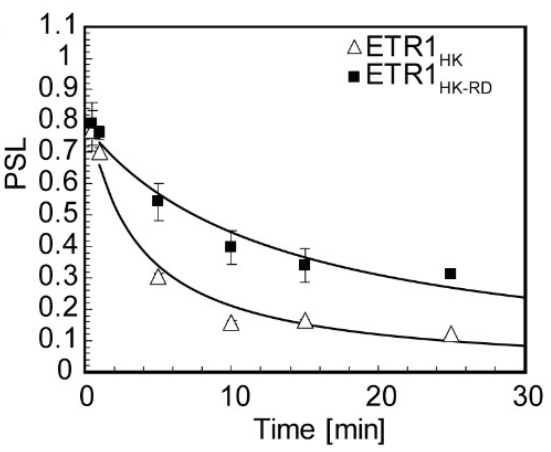

$\mathbf{F}$
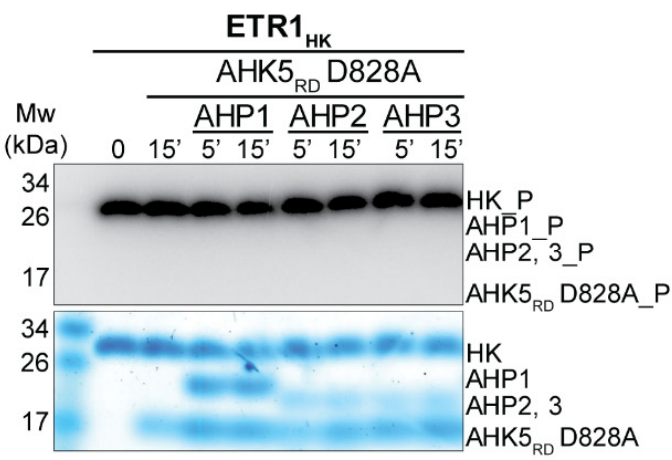

H

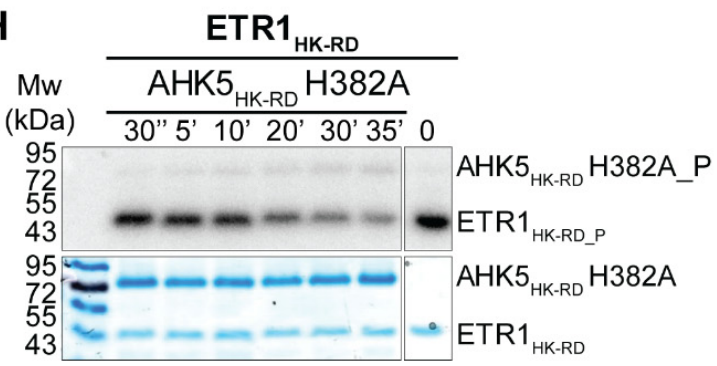

Figure 1. AHK5 $5_{R D}$ is a specific substrate for the histidine kinase activity of ETR1 and AHK5 is able 
Phosphotransfer from ETR1 $1_{H K}$ to $A H K 5_{R D}(A)$ and from ETR1 $1_{H K}$ to $C K I 1_{R D}(B)$. Phosphotransfer is apparent after just $30 \mathrm{~s}$ of incubation in $\mathrm{A}$. The last three lanes in $\mathrm{A}$ and $\mathrm{B}$ show $\mathrm{ETR} 1_{\mathrm{HK}}$ or $\mathrm{AHK} 5_{\mathrm{RD}} / \mathrm{CKI} 1_{\mathrm{RD}}$ only at the indicated time points after autophosphorylation. (C) Comparison of phosphotransfer kinetics from $\operatorname{ETR} 1_{\mathrm{HK}}$ to $\operatorname{AHK}_{\mathrm{RD}}(\Delta)$ and $\mathrm{CKI}_{\mathrm{RD}}(\mathbf{\square})$ estimated as GLM models based on the disappearance from ETR1 $1_{\mathrm{HK}}$ of the photostimulated luminescence (PSL) signal. Each point is the average of three replicates, error bars show standard error of the mean. (D) Comparison of phosphotransfer kinetics from $\operatorname{ETR} 1_{\mathrm{HK}}(\Delta)$, and $\operatorname{ETR} 1_{\mathrm{HK}-\mathrm{RD}}(\mathbf{\square})$, respectively, to $\mathrm{AHK}_{\mathrm{RD}}$; curves estimated as in C. (E) Phosphate transfer from ETR1 $1_{\mathrm{HK}}$ to AHPs through $A H K 5_{R D}$ and $(F)$ through $A H K 5_{R D}$ D828A. Time 0 means immediate addition of stopping buffer into the reaction. (G) Phosphotransfer from ETR1 $1_{H K-R D}$ to $A H K 5_{H K-R D}$ and (H) AHK5 $5_{H K-R D} H 382 A$ was performed as in $A$ and $B$, respectively. In $A-B$ and $E-H$, the top panels are autoradiograms following separation by SDS-PAGE. SDS-PAGE gels (12.5\%) stained with Coomassie-blue to show the amount of loaded proteins are shown below the autoradiograms. PageRuler Prestained Protein Ladder (ThermoFisher Scientific) was used as a molecular weight marker (Mw). The rightmost lane in $\mathrm{G}$ and $\mathrm{H}$ shows autophosphorylated ETR1 $1_{\mathrm{HK}-\mathrm{RD}}$ only. Asterisk $\left({ }^{*}\right)$ in $\mathrm{E}$ marks residual bacterial protein contamination. 
A

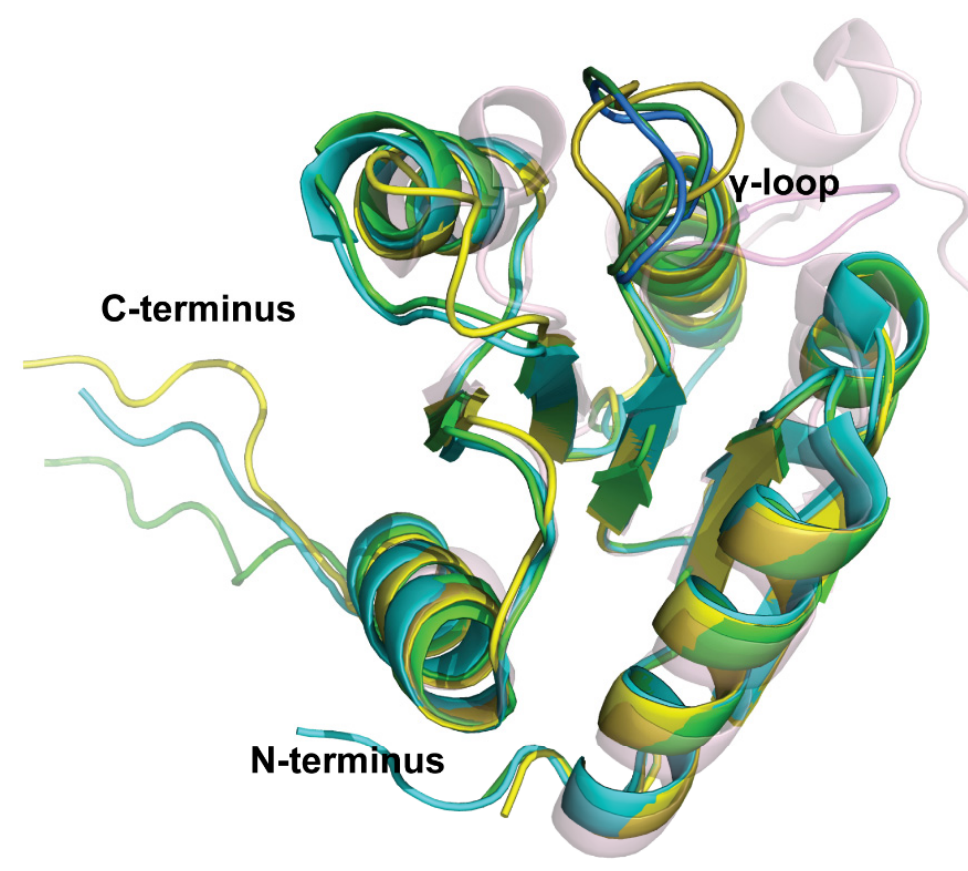

B
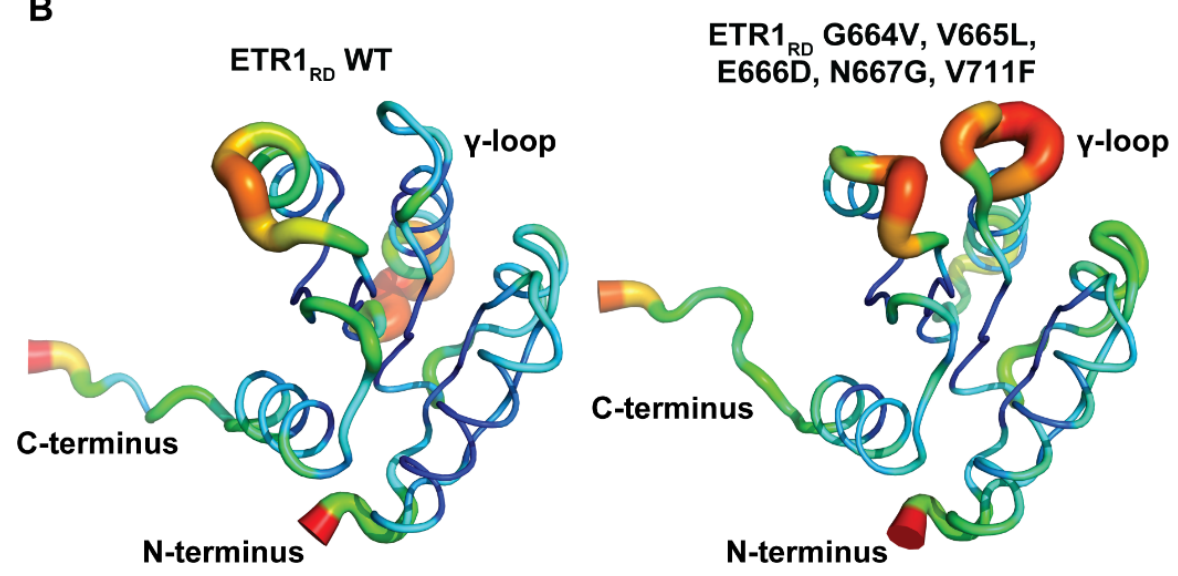

Figure 2. Mutant ETR1 $1_{\mathrm{RD}}$ with a $\beta 3-\alpha 3$ loop rewired to resemble that of $A H K 5_{\mathrm{RD}}$ is not able to accept phosphate from ETR1 $_{\mathrm{HK}}$ due to structural differences.

(A) Structural comparison of the ETR1 $1_{R D}$, quintuple mutant ETR1 $1_{R D}$ G664V, V665L, E666D, N667G, V711F and AHK5 $5_{R D}$. Green - ETR1 $1_{R D}$ WT (PDB 7PN2, this work), cyan - ETR1 $1_{R D}\left(P D B ~ 1 D C F^{9}\right)$, yellow - ETR1 $1_{R D}$ G664V, V665L, E666D, N667G, V711F (PDB 7PN3, this work), light pink - AHK5 RD $_{\text {(PDB }}$

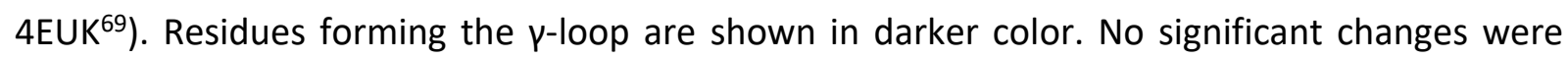
observed in the $\mathrm{Y}$-loop position between WT and ETR1 RD G664V, V665L, E666D, N667G, V711F. (B) ETR1 $1_{\mathrm{RD}}$ (left) and ETR1 $1_{\mathrm{RD}}$ G664V, V665L, E666D, N667G, V711F (right) shown based on relative 
B-factor (blue for minimum and red for maximum). Increased flexibility of the $\beta 3-\alpha 3$ loop of the mutant is highlighted using both color code and increased thickness of the line showing the peptide backbone.

\section{B}
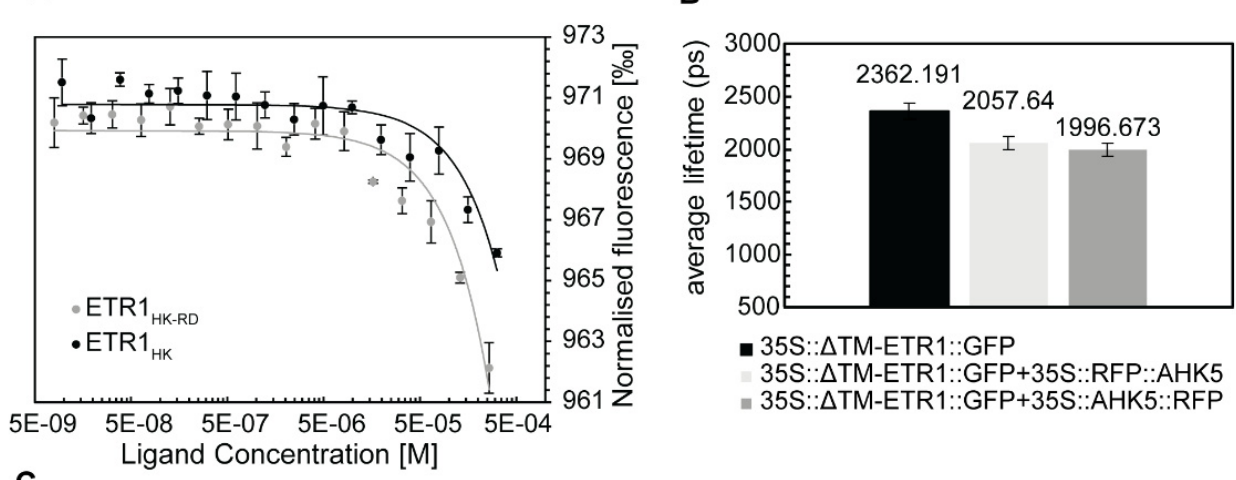

- 35S:: $\triangle T M-E T R 1:: G F P$

35S::DTM-ETR1::GFP+35S::RFP::AHK5 = 35S::АTM-ETR1::GFP+35S::AHK5::RFP

C

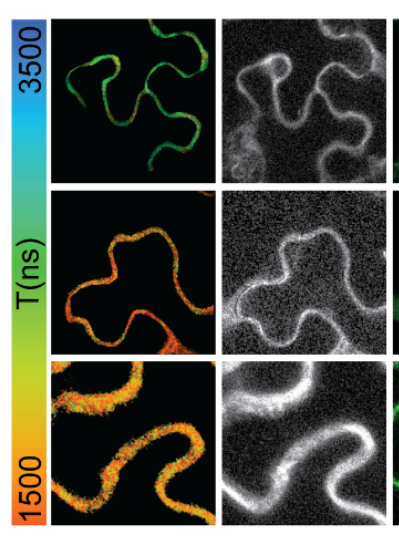

iii
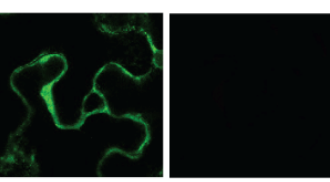

V

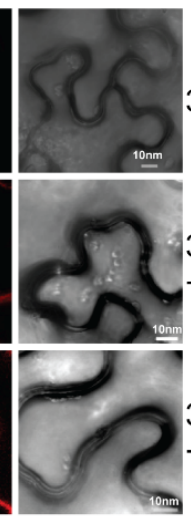

35S:: $\triangle T M-E T R 1:: G F P$

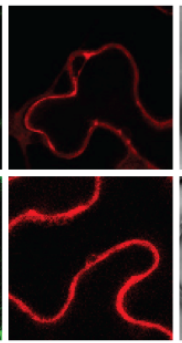

$35 \mathrm{~S}:: \triangle \mathrm{TM}-\mathrm{ETR} 1:: \mathrm{GFP}$

$+35 \mathrm{~S}::$ RFP::AHK5

35S:: $\triangle T M-E T R 1:: G F P$

$+35 \mathrm{~S}::$ AHK5::RFP

Figure 3. ETR1 interacts with AHK5 in vitro and in vivo.

(A) Dose response curves for AHK5 ${ }_{\mathrm{RD}}$-Alexa Fluor 488 binding to ETR1 $1_{\mathrm{HK}}$ and ETR $1_{\mathrm{HK}-\mathrm{RD}}$ using microscale thermophoresis (MST). The individual data points represent means of 3 replicates, error bars show standard deviation. Apparent $K_{D}$ measured by MST for the interaction of $A H K 5_{R D}$ with ETR1 $1_{\mathrm{HK}}$ and ETR1 $1_{\mathrm{HK}-\mathrm{RD}}$ is $166 \pm 78 \mu \mathrm{M}$ and $167 \pm 50 \mu \mathrm{M}$, respectively. (B) Average fluorescence lifetime of $\triangle$ TM-ETR1::GFP measured in transiently transformed $N$. benthamiana leaves with and without AHK5 tagged at the N- or C- terminal with RFP. (C) Lifetime images and corresponding confocal images of $\Delta$ TM-ETR1::GFP transiently expressed in $N$. benthamiana leaves i) intensity 
766 weighted color-coded lifetime image of $\triangle T M-E T R 1:: G F P$ ii) photon intensity weighted lifetime image iii) GFP channel of the corresponding confocal micrograph iv) RFP channel of the corresponding confocal micrograph showing AHK5 expression v) transmitted light channel. 

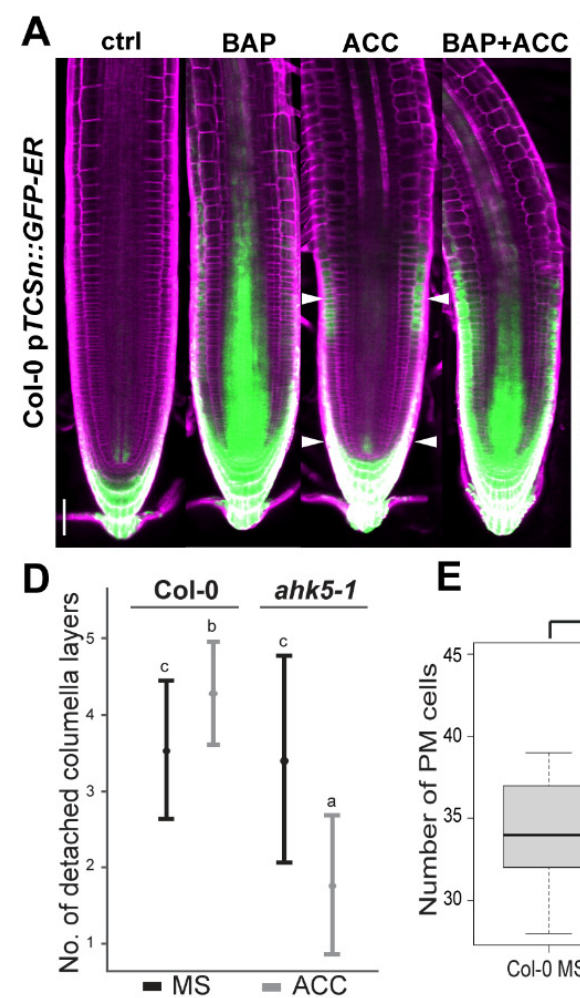

G

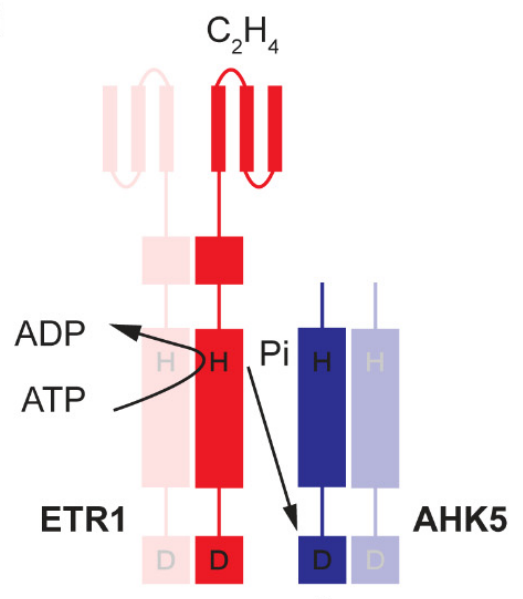<smiles>C1CCCCC1</smiles>

AHPs

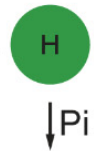

ARR-Bs

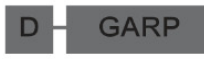

CELL DIVISION/DIFFERENTIATION<smiles>C1CCCCC1</smiles>

ROOT GROWTH

E
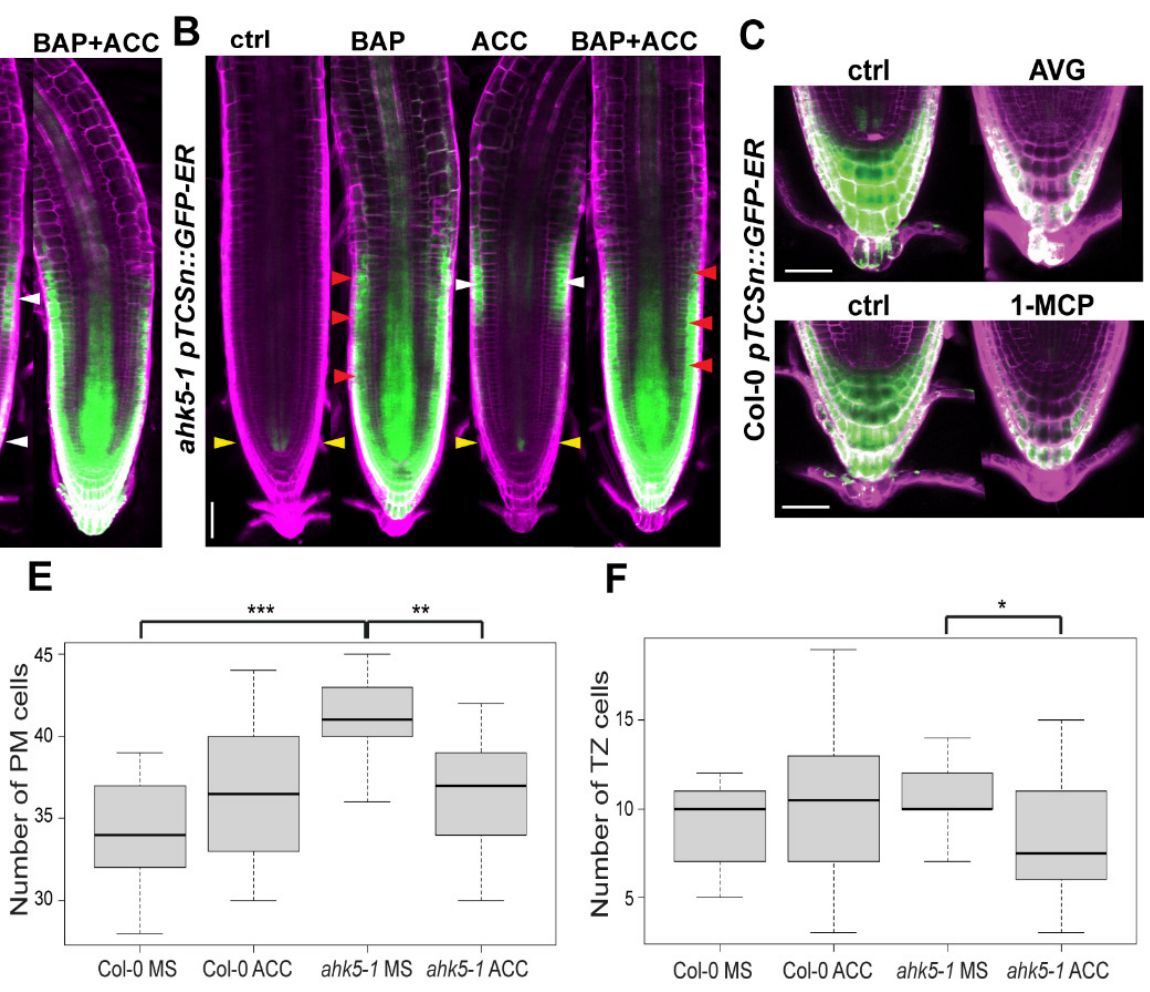

H

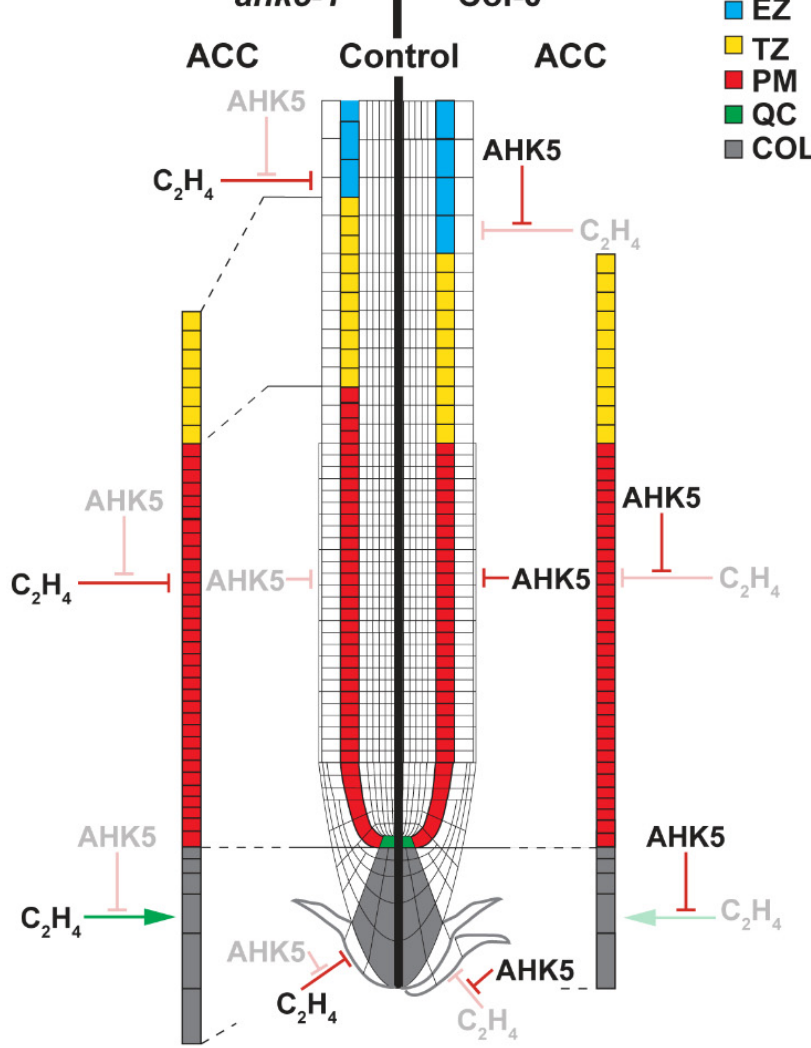


Figure 4. AHK5 is necessary for ethylene-mediated MSP activation in columella and lateral root cap. Expression pattern of ER-localized pTCSn-driven GFP in the WT Col-0 (A, C) and ahk5-1 (B) backgrounds after ( $5 \mu \mathrm{M}$ BAP, $5 \mu \mathrm{M}$ ACC, $5 \mu \mathrm{M}$ BAP + $5 \mu \mathrm{M}$ ACC, $1 \mu \mathrm{M}$ AVG, $2 \mu \mathrm{L} \cdot \mathrm{L}^{-1}$ 1-MCP and $0.1 \% \mathrm{DMSO} / \mathrm{MS}$ or air as control). The number of detached root cap layers of 10-day-old seedlings (D), proximal meristem size analysis (E) and number of TZ cells (F) were compared between Col-0 and ahk5-1 seedlings grown on MS media $\pm 1 \mu \mathrm{M}$ ACC. A model for the transphosphorylation crosstalk between ETR1 and AHK5 and its role in the hormonal regulation of root growth ( $\mathbf{G}$ and $\mathbf{H}$ ). The membrane signal from PI staining is shown in magenta; GFP is in green. White arrowheads in A and B mark the specific localization of the ACC-induced signal while the yellow arrowheads mark the positions where the ACC-induced signal is alleviated/missing in ahk5-1 roots. Red arrowheads mark the stronger TCS signal in the epidermis/cortex upon BAP treatment. Scale bar represents $50 \mu \mathrm{m}$. 